\title{
Results of a National Driver Registration Statistical Match
}

\author{
Kelly R. Buck \\ Defense Personnel Security Research Center \\ David A. Richmond \\ Defense Personnel Security Research Center \\ Howard E. Timm \\ Defense Personnel Security Research Center
}





\title{
Results of a National Driver Register Statistical Match
}

\author{
Kelly R. Buck \\ Defense Personnel Security Research Center \\ David A. Richmond \\ Defense Personnel Security Research Center \\ Howard E. Timm \\ Defense Personnel Security Research Center
}

\author{
Released By \\ James A. Riedel \\ Director
}





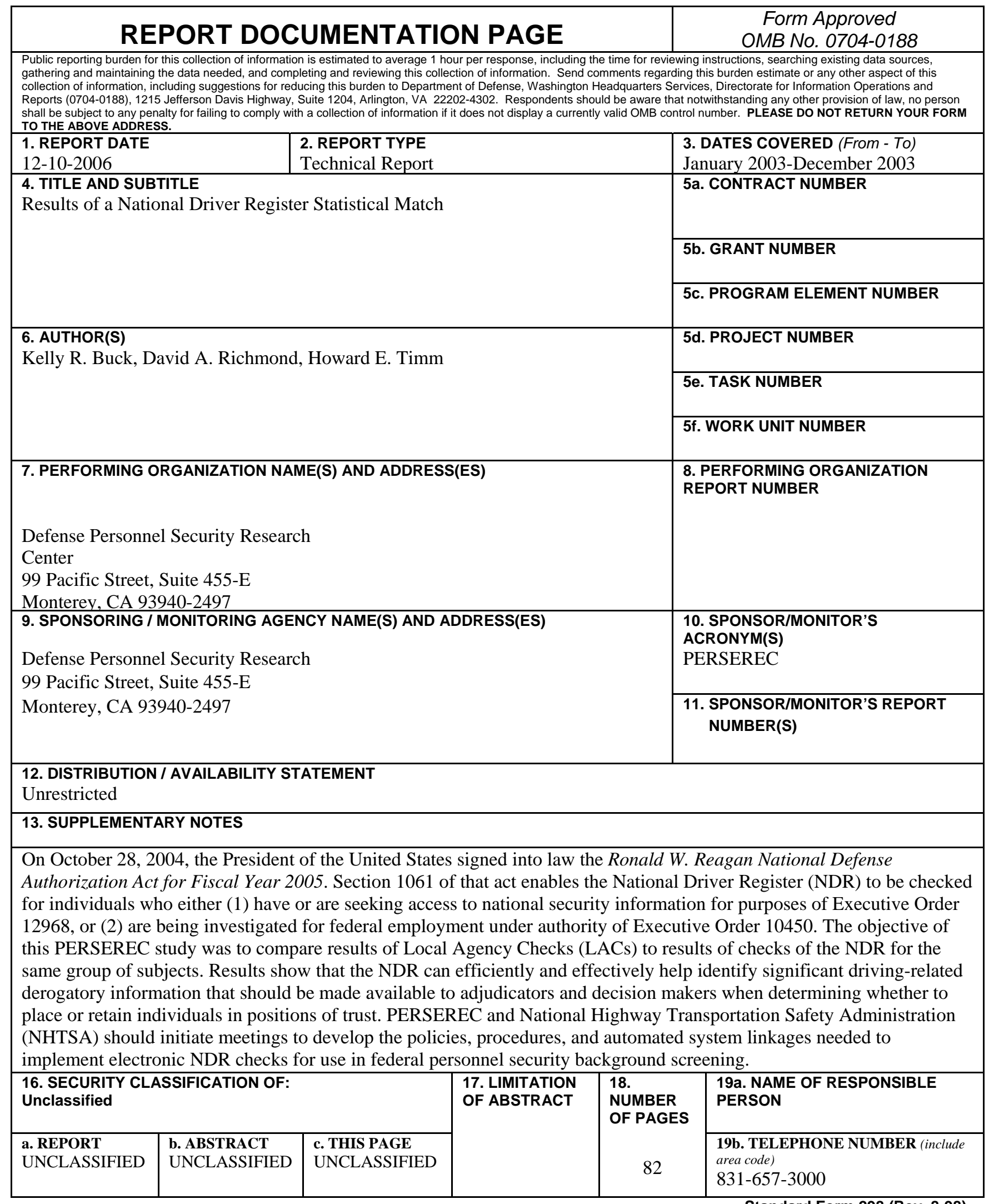





\section{Preface}

On October 28, 2004, the President of the United States signed into law the Ronald W. Reagan National Defense Authorization Act for Fiscal Year 2005. Section 1061 of that Act enables the National Driver Register (NDR) to be checked for individuals who either (1) have or are seeking access to national security information for purposes of Executive Order No. 12968 or (2) are being investigated for federal employment under authority of Executive Order No. 10450.

This study demonstrates that the NDR has potential for identifying additional significant derogatory information that should be made available to adjudicators when making determinations about whether to place or retain individuals in positions of trust. The NDR data will overcome vulnerabilities by insuring checks of local and state record systems in locations where offenses occur and by providing information about all relevant facts for subjects who have not been forthcoming about negative information in their backgrounds.

The Defense Personnel Security Research Center (PERSEREC) and the National Highway Transportation Safety Administration (NHTSA) of the U.S. Department of Transportation (DOT) should move forward with meetings to develop the policies, procedures, and automated system linkages needed to implement electronic NDR checks for use in federal personnel security background screening.

James A. Riedel

Director 


\section{Acknowledgements}

PERSEREC would like to thank the National Highway Transportation Authority (NHTSA) for its assistance in conducting the statistical match. In particular, we would like to recognize Christine Holdsworth for highly competent and conscientious contributions of data, advice, and analyses. 


\section{Executive Summary}

\section{Purpose of the Study}

On October 28, 2004, the President of the United States signed into law the Ronald W. Reagan National Defense Authorization Act for Fiscal Year 2005. Section 1061 of that Act enables the National Driver Register (NDR) to be checked for individuals who either (1) have or are seeking access to national security information for purposes of Executive Order No. 12968 or (2) are being investigated for federal employment under authority of Executive Order No. 10450. The purpose of this study is to assess the value of incorporating checks of the National Highway Transportation Safety Authority's (NHTSA) NDR in Department of Defense (DoD) security clearance background investigations.

The National Driver Register (NDR) is a central index covering all 50 states and the District of Columbia that is maintained by the US Department of Transportation (DOT). According to 49 USC 30304, the chief driver licensing official in each participating state is required to report each individual falling under their jurisdiction:

(1) Who is denied a motor vehicle operator's license by that state for cause;

(2) Whose motor vehicle operator's license is revoked, suspended, or canceled by that state for cause; or

(3) Who is convicted under the laws of that state of any of the following motor vehicle-related offenses or comparable offenses:

(a) Operating a motor vehicle while under the influence of, or impaired by, alcohol or a controlled substance.

(b) A traffic violation arising in connection with a fatal traffic accident, reckless driving, or racing on the highways.

(c) Failing to give aid or provide identification when involved in an accident resulting in death or personal injury.

(d) Perjury or knowingly making a false affidavit or statement to officials about activities governed by a law or regulation on the operation of a motor vehicle.

\section{Methodology}

The NHTSA agreed to conduct a statistical match using the NDR to identify the proportion of a sample of DoD security clearance applicants who are indexed in their system as having one or more NDR reportable driving-related issues. The Defense Personnel Security Research Center (PERSEREC) provided the NHTSA with a sample of 23,854 subjects from the population of security clearance investigations opened in calendar years 2002 (CY02) or 2003 (CY03). These years were selected because the NDR only indexes driving violations for three years. 
The NHTSA matched the personal identifiers and aliases for this sample against their index and returned a database populated with an indicator of the existence or absence of an NDR issue being recorded in the same states for the same individual as contained in the DoD sample. Additionally, the returned data included an indicator of NDR record matches in any state for each individual in the DoD sample. The matched sample was returned to DoD minus personal identifiers and other variables that could have enabled the DoD to match the NDR data to specific individuals in the DoD population. Variables that were included in the matched sample indicated whether subjects had either (1) self-reported any one of several significant issues or (2) been associated with serious driving offenses or other crimes identified during the course of local or state agency checks.

\section{Results}

In the 257,067 investigations that opened in 2002 or 2003 and that had valid state data for the location of criminal record checks, based only on LACs, 13,625 record checks representing 12,957 individuals across the 50 states and Puerto Rico resulted in detection of a record of a driving offense that could be reported to the NDR. Based on sample match results, adding the use of the NDR to these LACs would potentially result in the identification of 41,827 subjects with serious driving offense records in at least one state. In other words, without the NDR, investigators are failing to identity approximately two thirds of the identifiable subjects with serious driving-related issues.

\section{Recommendations}

PERSEREC and the NHTSA of the DOT should initiate meetings to develop the policies, procedures, and automated system linkages needed to implement electronic NDR checks for use in federal personnel security background screening. 


\section{Table of Contents}

Introduction__ 1

Methodology _ 3

Sampling Strategy ___ 6

Coding Results of “Any Criminal Offense” Using ROIs of Criminal Record Checks

Coding Results of “Any Driving Offense” Using ROIs of Criminal Record Checks

Coding of “Any Self-Report” Responses to Questions about Significant Issues 8

Coding Results of the NDR Match

Method of Analysis

Results

Comparison of LACs and the NDR in States Where Investigators Knew to

Conduct LACs

Comparison of the Effectiveness of LACs and the NDR Checks Regardless of

Where Investigators Knew to Conduct LACs 10

Distribution of Types of Offenses in the NDR for the Sample 11

Discussion and Recommendations 12

References 15

\section{Appendices}

Appendix A: NDR For Cause Withdrawal and Conviction Codes

Appendix B: Method of Coding Results of Record Checks

Appendix C: Complete Statistical Match Results and Analysis, Record Level, by State C-1

Appendix D: Complete Statistical Match Results and Analysis, Individual Level, by State D-1 


\section{List of Tables}

1. Demographic Characteristics 4

2. Case Summary 5

3. Distributions for Control Variables 6

4. Comparison of Results of LACS with NDR Checks, Controlling for State in Which LACs Conducted

5. Comparison of Number of Subjects Identified by LACs and NDR Checks Regardless of Where LACs Were Conducted

6. Offenses Indexed in the NDR for the Sample 12

A-1. NDR For Cause Withdrawal and Conviction Codes A-3

C-1. Complete Statistical Match and Analysis Results, Record Level C-3

D-1. Complete Statistical Match and Analysis Results, Subject Level D-3

E-1. Sample Totals, Aggregated by Subject E-3

E-2. Population Totals, Aggregated by Subject E-3

E-3. Population Estimates E-4

\section{List of Figures}

B-1. Example of Reports of Investigation When Criminal Records Are Found B-3

B-2. Example of Reports of Investigation When Criminal Records Are Not Found B-4 


\section{Introduction}

On October 28, 2004, the President of the United States signed into law the Ronald W. Reagan National Defense Authorization Act for Fiscal Year 2005. Section 1061 of that Act enables the National Driver Register (NDR) to be checked for individuals who either (1) have or are seeking access to national security information for purposes of Executive Order No. 12968 or (2) are being investigated for federal employment under authority of Executive Order No. 10450. The purpose of this study is to assess the value of incorporating checks of the National Highway Transportation Safety Authority's (NHTSA) NDR in Department of Defense (DoD) security clearance background investigations.

The National Driver Register (NDR) is a central index covering all 50 states and the District of Columbia that is maintained by the US Department of Transportation. According to 49 USC 30304, the chief driver licensing official in each participating state is required to report each individual falling under their jurisdiction:

(1) Who is denied a motor vehicle operator's license by that state for cause;

(2) Whose motor vehicle operator's license is revoked, suspended, or canceled by that state for cause; or

(3) Who is convicted under the laws of that State of any of the following motor vehicle-related offenses or comparable offenses:

(a) Operating a motor vehicle while under the influence of, or impaired by, alcohol or a controlled substance.

(b) A traffic violation arising in connection with a fatal traffic accident, reckless driving, or racing on the highways.

(c) Failing to give aid or provide identification when involved in an accident resulting in death or personal injury.

(d) Perjury or knowingly making a false affidavit or statement to officials about activities governed by a law or regulation on the operation of a motor vehicle.

PERSEREC and the DOT National Highway Transportation Safety Authority (NHTSA) conducted a statistical match to assess the value of the NHTSA's National Driver Register (NDR) for DoD personnel security investigations (PSIs). The NDR contains an index to state records of serious driving-related violations which may be germane to making security clearance determinations. The purpose of this report is to evaluate the value of the NDR for personnel security clearance background investigations, describe the statistical match process used to assess the potential value of the NDR, and report the extent to which use of the NDR may add valuable data to PSIs. 
The NDR is a central index of individuals whose driver's licenses have been denied, revoked, suspended, or canceled for cause or who have been convicted of serious driving-related offenses such as driving while intoxicated, racing, leaving the scene of an accident, perjury, or use of a vehicle in the commission of a felony. ${ }^{1}$ (For a full list of offenses, refer to Appendix A). The NDR traditionally has been used by state licensing authorities and employers of persons providing transportation services to determine whether applicants have valid licenses or have been convicted of offenses that may bear on their employability or ability to be licensed.

The NDR would also be of use in the screening of persons for positions of trust. In keeping with Executive Order 12968, authorities are required to grant national security clearances only to trustworthy and reliable people. All the persons reported to the NDR have at least one offense that relates directly to adjudication criteria. For example, drug and alcohol problems may be indicated by arrests for driving while under the influence. Perjury clearly relates to standards of personal conduct to be truthful. Use of a vehicle in the commission of a felony is a driving-related offense that may lead to detection of a serious criminal offense that might have otherwise remained unknown. Protecting national security by ensuring that only qualified personnel are granted access to sensitive information and facilities is in the best interests of all federal agencies, not to mention the people of the United States.

Currently, identification of the types of serious driving-related offenses described above relies on subjects self-disclosing them and on checks of local and state law enforcement databases. Investigators go to locations where applicants self-disclose offenses and/or to locations where subjects are known to have lived, worked, or attended school for a scope of time specified for their type of security clearance background investigation.

The problem with this strategy is that many offenses of concern may occur in places that fall outside the scope of investigative requirements but within the scope of adjudicative consideration. For example, an individual who lives, works, and goes to school in San Jose, CA, may be charged with DUI while partying in San Francisco, a popular destination a little over an hour away. Under current investigative requirements (DoD 5200-R), records checks would not be conducted in San Francisco if the individual has neither lived, worked, nor gone to school there during the years covered by the investigation. Unless the individual self-reports the offense, investigators and adjudicators would not know about it. Because it is statewide and even national in scope, the NDR holds promise for improving the effectiveness of background screening of personnel for positions of trust.

\footnotetext{
${ }^{1}$ The NDR does not contain the actual records of individuals, but serves as a pointer system to state departments of transportation or motor vehicles where the complete records can be requested (NDR Act of 1982, Pub. L. 97-364, 96 Stat. 1740, as amended (49 U.S.C. 30301 et seq.)). This system is called the National Driver Register Problem Driver Pointer System (56 FR 41394 (1991)). It is fully automated and provides responses to electronic queries instantaneously (23 CFR Part 1327 (2004)). The Pointer System contains personal identifiers of problem drivers, states in which reportable problems occurred, and violation codes used by all states and the NDR (see Appendix A).
} 
Relying on self-reports is also problematic. Research by PERSEREC has shown that a significant proportion of subjects do not self-disclose offenses as required in their security clearance applications (Buck \& Reed, 2003; Buck \& Rose, 2004). For these reasons, access to the NDR would, through an efficient means, improve the effectiveness of personnel security clearance investigations by surfacing information that may bear on individuals' suitability and trustworthiness for positions of trust and access to classified information.

Single-source automated queries by DoD of the NDR might also alleviate some of the existing burden on state driver-licensing personnel. DoD envisions having a central electronic interface between DoD and NDR via a means such as the Automated Continuing Evaluation System (ACES). In addition to the benefits applicable for background investigations, an electronic link could also potentially alleviate future and any existing burdens on state driver-licensing officials to respond to driving-related record requests from investigators requesting record checks during the course of federal national security clearance investigations. Specific state agencies would only be queried in the event a record is identified in the NDR pointer system.

Another advantage of using the NDR is that it could serve as another means of deterring problematic driving among cleared personnel. If DoD and other agencies start to use this information in making security clearance determinations, transportation safety will be enhanced because the 3.5 million people with security clearances will want to make sure they do not get into clearance trouble based on driving misconduct. They know that they will ultimately be held accountable to answer for driving violations in the course of their security clearance investigations, reinvestigations, and continuous monitoring.

Before Section 1061 of the Ronald W. Reagan National Defense Authorization Act for Fiscal Year 2005 was signed into law, the DoD with the cooperation of the NHTSA began conducting a statistical match to determine the extent to which the NDR could help identify serious vehicle code violations and convictions that are presently being missed by current methods for conducting security clearance background investigations. The following section describes the methodology used to conduct the match. Results and recommendations follow.

\section{Methodology}

The data used in this study were obtained from three sources: (1) Reports of Investigation (ROIs) for security clearance applicants whose cases were opened by the Defense Security Service (DSS) in calendar year 2002 or 2003, (2) subjects' responses on their Electronic Personnel Security Questionnaires (EPSQs) as recorded in the DoD Case Control Management System (CCMS), and (3) the United States Department of Transportation (DOT) National Highway Transportation Safety Authority (NHTSA) National Driver Registry (NDR). 
There were 256,849 unique individuals in the population, from which a sample of 23,854 individuals was drawn. Summaries of the demographic characteristics of these individuals for the population and the sample are provided in Table 1 . ROIs provided the data on years cases were opened, the states with which records are associated, subject

Table 1 Demographic Characteristics $^{\mathrm{a}}$

\begin{tabular}{|c|c|c|c|c|}
\hline & \multicolumn{2}{|c|}{$\begin{array}{c}\text { Population } \\
(N=256,849)\end{array}$} & \multicolumn{2}{|c|}{$\begin{array}{c}\text { Sample } \\
(n=23,854)\end{array}$} \\
\hline & $N$ & $\%$ & $n$ & $\%$ \\
\hline \multicolumn{5}{|l|}{ Age } \\
\hline Under 20 & 37,924 & 14.77 & 2,982 & 12.50 \\
\hline $20-29$ & 67,722 & 26.37 & 7,501 & 31.45 \\
\hline $30-39$ & 68,203 & 26.55 & 6,806 & 28.53 \\
\hline $40-49$ & 51,861 & 20.19 & 4,437 & 18.60 \\
\hline $50-59$ & 25,300 & 9.85 & 1,816 & 7.61 \\
\hline $60-69$ & 5,317 & 2.07 & 293 & 1.23 \\
\hline 70 or older & 522 & 0.20 & 19 & 0.08 \\
\hline \multicolumn{5}{|l|}{ Sex } \\
\hline Female & 43,799 & 17.05 & 3,078 & 12.90 \\
\hline Male & 209,682 & 81.64 & 20,460 & 85.77 \\
\hline Unknown & 3,368 & 1.31 & 316 & 1.32 \\
\hline \multicolumn{5}{|c|}{ Employee Type } \\
\hline Civilian & 987 & 0.38 & 68 & 0.29 \\
\hline Industrial & 86,725 & 33.76 & 6,900 & 28.93 \\
\hline Military & 169,137 & 65.85 & 16,866 & 70.79 \\
\hline
\end{tabular}

social security number, name, gender, age, place of birth, military status (civilian, military, or industrial), type of investigation (SSBI, SSBI-PR, NACLC-C, NACLC-S, etc.), and whether the case was considered "added coverage" "issue" or "nonissue" by DSS.

This study included only ROIs for cases that opened in 2002 or 2003 and that had valid state data for the location of criminal record checks. The resulting dataset had 409,265 cases, where a case equals one record check. Subjects may appear more than once in the data, since they may be associated with more than one record check.

The population of 256,849 individuals is associated with 257,067 cases; the sample of 23,854 individuals is associated with 23,863 cases. A few individuals are associated with multiple cases opening within the time period of the study: CY02 and 
CY03. Table 2 presents the distributions of cases as well as the distribution of issue, nonissue, and added coverage cases in the population and sample.

Table 2

Case Summary ${ }^{\mathrm{a}}$

\begin{tabular}{|c|c|c|c|c|}
\hline & \multicolumn{2}{|c|}{$\begin{array}{l}\text { Population }^{b} \\
(N=257,067)\end{array}$} & \multicolumn{2}{|c|}{$\begin{array}{c}\text { Sample }^{b} \\
(n=23,863)\end{array}$} \\
\hline & $N$ & $\%$ & $n$ & $\%$ \\
\hline \multicolumn{5}{|l|}{ Case Type } \\
\hline NACLC-Trustworthiness & 578 & 0.22 & 46 & 0.19 \\
\hline NACLC-Confidential & 2,356 & 0.92 & 233 & 0.98 \\
\hline NACLC-PR-Confidential & 534 & 0.21 & 32 & 0.13 \\
\hline NACLC-Secret & 128,712 & 50.07 & 12,600 & 52.80 \\
\hline NACLC-PR-Secret & 58,442 & 22.73 & 5,338 & 22.37 \\
\hline SSBI & 30,652 & 11.92 & 3,130 & 13.12 \\
\hline SSBI-PR & 34,825 & 13.55 & 2,303 & 9.65 \\
\hline Other & 968 & 0.38 & 181 & 0.76 \\
\hline Total & 257,067 & 100.00 & 23,863 & 100.00 \\
\hline \multicolumn{5}{|l|}{ Issue } \\
\hline Nonissue & 207,150 & 80.58 & 15,098 & 63.27 \\
\hline Issue case & 48,279 & 18.78 & 8,486 & 35.56 \\
\hline Added Coverage & 1,638 & 0.64 & 279 & 1.17 \\
\hline Total & 257,067 & 100.00 & 23,863 & 100.00 \\
\hline
\end{tabular}

Note that Table 2 shows disproportionately more issue cases in the sample than in the population. As will be described in the next section, cases with offenses detected in LACs were intentionally oversampled. The distribution of case type, however, is very similar between the population and sample. The sample has a slightly lower proportion of SSBI and SSBI-PRs (approximately 25\%), and a slightly higher proportion of NACLCSecret investigations (approximately 75\%), reflecting the differences in likelihood of issues occurring in these kinds of cases. 


\section{Sampling Strategy}

Initially, PERSEREC was interested in running a statistical match on the entire population of cases opened in CY02 and CY03. This strategy was not practical for the NHTSA, however, so a target sample of approximately 30,000 DoD record checks was drawn for comparison with the NDR. This sample size was the largest that the NHTSA indicated they could accommodate.

Sampling was conducted randomly within states, as well as within certain conditions reflecting whether or not subjects had issues of security concern identified during the course of their investigation. Most of these issues of concern pertained to criminal conduct; some pertained to significant financial distress or civil judgments. (For more information, see the Section entitled Coding of “Any Self-Report” Responses to Questions about Significant Issues,” below.)

Two other variables were coded for subjects within each state. One was whether investigators' written ROIs indicated that subjects had any type of criminal citation, arrest, or conviction ("Any Criminal Offense”). The second was whether this criminal issue included a driving offense of the type that is authorized to be reported to the NDR ("Any Driving Offense"). Table 3 shows the distributions for these variables for the population and for the sample. More specific information about how they were coded is provided in the sections following.

Table 3

Distributions for Control Variables ${ }^{\mathrm{a}}$

\begin{tabular}{|c|c|c|c|c|}
\hline & \multicolumn{2}{|c|}{$\begin{array}{c}\text { Population } \\
(N=256,849)\end{array}$} & \multicolumn{2}{|c|}{$\begin{array}{c}\text { Sample } \\
(n=23,854)\end{array}$} \\
\hline & $N$ & $\%$ & $n$ & $\%$ \\
\hline \multicolumn{5}{|c|}{ Any Self-Report } \\
\hline No & 204,137 & 79.5 & 12,241 & 51.3 \\
\hline Yes & 51,867 & 20.2 & 11,613 & 48.7 \\
\hline Missing & 845 & 0.3 & 0 & 0.0 \\
\hline \multicolumn{5}{|c|}{ Any Criminal Offense } \\
\hline No & 216,240 & 84.2 & 10,850 & 45.5 \\
\hline Yes & 40,609 & 15.8 & 13,004 & 54.5 \\
\hline Missing & 0 & 0.0 & 0 & 0.0 \\
\hline \multicolumn{5}{|c|}{ Any Driving Offense } \\
\hline No & 240,795 & 93.7 & 19,416 & 81.4 \\
\hline Yes & 13,049 & 5.1 & 4,159 & 17.4 \\
\hline Missing & 3,005 & 1.2 & 279 & 1.2 \\
\hline
\end{tabular}


The resulting DoD dataset had 40,742 record checks, representing 23,854 unique individuals. The DoD dataset was sent to NHTSA for matching. Each individual in the DoD dataset was identified by first, middle, and last name, aliases, date of birth, and social security number. Two additional data fields were appended to the dataset by NHTSA. Those data fields indicated whether each subject: (1) had a driving offense record indexed in the NDR from the same state where security clearance investigators conducted the record check submitted for matching by the NDR, and (2) had a driving offense indexed in the NDR from any state, regardless of whether security clearance investigators conducted checks in those states. In addition to those two data elements added by NHTSA, the returned data included the variables "Any Criminal Offense," "Any Driving Offense," and "Any Self-Report” from the original data submitted by DoD. All personal identifiers were removed by the NHTSA staff prior to returning the data to PERSEREC.

\section{Coding Results of “Any Criminal Offense” Using ROIs of Criminal Record Checks}

Coding of LACs was done using Peak Software’s ALICE data mining application. ALICE was programmed to search and flag ROIs for key words pertaining to criminal and driving offenses. The resulting data were coded as having any kind of offense record or no record using logical indicators such as field length and patterns in phrases consistently used by investigators such as "was arrested on," "paid fine of," "dismissed," "plead guilty," "was acquitted,” or "was convicted.” These ROI results were then reviewed. Miscoded data were cleaned both manually and electronically using Microsoft Visual Basic macros. More detailed descriptions of the method of coding ROIs are provided in Buck (2004) and Buck and Rose (2004). An excerpt from Buck (2004) is provided in Appendix B.

\section{Coding Results of “Any Driving Offense” Using ROIs of Criminal Record Checks}

Subjects categorized as having any kind of driving offenses discovered during their local and state record checks were identified through procedures similar to those used to identify subjects with any kind of criminal involvement. For the driving offenses, however, the focus was limited to those types of offenses covered by the NDR, and to the time period that NHTSA is authorized to retain such records. Subjects identified as having driving offenses in the original DoD data set had local agency record checks that surfaced one or more of the following types of events: drinking and driving; driving without a license or on a suspended or revoked license; reckless driving; hit and run.

The above list does not include all offenses covered by the NDR. The reason for this has to do with ambiguities in interpretation of text in ROIs. Only offenses that clearly fell into a clearly reportable NDR category were included. Additionally, some offenses occurred so rarely in the DoD CCMS database that they could not be used in sampling without enabling the NDR-provided data to be linked to specific individuals regardless of the exclusion of personal identifiers. One of the conditions of the study for NHTSA's participation was that they would not return NDR match results if these could be associated with particular individuals. 
Additionally, only driving offenses occurring within 3 years preceding the date the sample was drawn (July 2004) were included, since only offenses 3 years old or less are included in the NDR. Therefore, only cases having driving offenses that occurred during the years 2001, 2002, or 2003 were coded as having a driving-related offense.

\section{Coding of “Any Self-Report” Responses to Questions about Significant Issues}

In addition to controlling for subjects known to have arrest or conviction records for any criminal offense and for the aforementioned driving offenses, the study controlled for the extent to which subjects self-reported significant issues on the EPSQs. The following yes/no questions on the EPSQ were selected for each individual in the data:

- Have you ever been charged with or convicted of any felony offense?

- Have you ever been charged with or convicted of a firearms or explosives offense?

- Are there currently any charges pending against you for any offense?

- Have you ever been charged with or convicted of any offense(s) related to alcohol or drugs?

- In the last 7 years, have you been subject to court martial or other disciplinary proceedings under the Uniform Code of Military Justice?

- In the last 7 years, have you been arrested for, charged with, or convicted of, any offense(s) not listed in modules 21, 22, 23, 24, or 25? (Leave out traffic fines of less than $\$ 150.00$ unless the violation was alcohol or drug related.)

- In the last 7 years, have you filed a petition under any chapter of the bankruptcy code (to include Chapter 13)?

- In the last 7 years, have you had your wages garnished for any reason?

- In the last 7 years, have you had any property repossessed for any reason?

- In the last 7 years, have you had a lien placed against your property for failing to pay taxes or other debts?

- In the last 7 years, have you had any judgments against you that have not been paid?

- In the last 7 years, have you been a party to any public record civil court actions not listed elsewhere on this form?

An indicator was created (“Any Self-Report”) which was true if the subject gave a "yes" response to any of the above EPSQ items and false if the subject responded "no" to all of the selected items. The purpose of the Any Self-Report variable was to provide another layer of control for whether subjects were issue cases or not. 


\section{Coding Results of the NDR Match}

As previously noted, the NHTSA returned results of the match for the sample reported in two ways. One measure indicated whether the NDR had a record in the same state where a given LAC was conducted. The second measure indicated whether the NDR had a record for a subject in any state, regardless of where LACs were conducted. The first measure provides a means of assessing the value of the NDR in states where investigators knew to conduct LACs. The second measure indicates the extent to which the NDR found more or less information than obtained by DoD's LAC strategy as a whole, regardless of where LACs were conducted.

\section{Method of Analysis}

To assess the degree of consistency between the NDR and LACs conducted within given states, the proportion of records and subjects with and without evidence of any self-reported significant issue, any criminal record, and/or any driving offense were calculated for both the sample and the population within each state. The percent of sample subjects identified by the NHTSA as having an NDR record within a given state was calculated for each condition for the sample. These percentages were then applied to relevant conditions for the population to arrive at an estimate of the number of additional records and individuals who would be expected to identified by the NDR as having significant driving problems. These additional NDR hits reflect issues of security concern that would have otherwise gone undetected using existing procedures for conducting local and state criminal record checks.

\section{Results}

\section{Comparison of LACs and the NDR in States Where Investigators Knew to Conduct LACs}

The sample set sent to the NHTSA included 4,159 subjects who were identified by 4,280 local and state agency checks as having significant driving issues. NDR checks for the sample identified 1,393 additional individuals with significant driving issues. Therefore, out of the sample for the study, using both LACs and NDR, 5,870 subjects are believed to have significant driving records. Of these 5,870 subjects with problematic driving records, a total of $71 \%$ were identified by local and state agency checks whereas $59 \%$ were identified by NDR checks. The NDR and local and state agency checks in common identified 2,056 subjects, or $27 \%$ of possible driving offenders. The proportion identified by LACS relative to the NDR is higher in the sample due to oversampling of subjects with serious driving records.

The proportions of subjects identified by the NDR within states for the sample were applied to the population record and subject totals to derive the data reported under the population header in Table 4. Without the NDR, investigators identified 13,607 subjects with driving records that could be reported to the NDR. With added use of the 
NDR, 31,251 would have been identified, a potential increase of approximately 17,644 subjects. Of all subjects expected to have serious driving records based on LACs and checks of the NDR, the NDR would be expected to identity 74\% while LACs would identify 44\%. The data used in calculations for Table 4 are provided in Appendix C (by state and by record check) and Appendix D (aggregated within states by subject).

Table 4

Comparison of Results of LACS with NDR Checks, Controlling for State in Which LACs Conducted

\begin{tabular}{lrrrr}
\hline & \multicolumn{2}{c}{ Sample } & \multicolumn{2}{c}{ Population } \\
\cline { 2 - 5 } & Records & Subjects $^{a}$ & Records $^{\text {Subjects }}$ \\
\hline Total number identified by LACs & 4,280 & 4,159 & 13,625 & 13,607 \\
Total number identified by NDR & 3,739 & 3,449 & 23,320 & 23,287 \\
Total number identified in common & 1,738 & 2,056 & 5,669 & 5,661 \\
Total number identified by LACs \& NDR combined & 6,281 & 5,870 & 31,276 & 31,251 \\
Pct. of combined total identified by LACs & 68.1 & 70.9 & 43.6 & 43.6 \\
Pct. of combined total identified by NDR & 59.5 & 58.8 & 74.6 & 74.5 \\
\hline
\end{tabular}

${ }^{\mathrm{a}}$ Includes 558 subjects for whom significant driving records were found by LACs conducted in more than one state.

The relative proportion of records and subjects identified by LACs and by the NDR are reversed when comparing results for the sample and the population. This reversal is due to the sampling methods used for the study. In selecting cases for the statistical match, cases with any known criminal offense or any driving offense were oversampled to get a sense of the extent to which known records would be identified by the NDR. The logic of the analysis, however, focused on the percentages of the clean populations within each state that were identified as having significant driving records by the NDR. Once these percentages were extrapolated to the population, controlling for state populations, the number of records and subjects identified by the NDR was relatively higher.

The above results apply only to the record checks actually conducted by DSS or OPM investigators and, therefore, only apply to those checks in states, counties, and municipalities where the investigators knew to conduct a LAC. The value of the NDR, however, is that it can identity offenders even in states where investigators have no indication based on subject self-reports or investigative requirements that a LAC should be conducted.

\section{Comparison of the Effectiveness of LACs and the NDR Checks Regardless of Where Investigators Knew to Conduct LACs}

Table 5 shows the number of subjects over all states who were identified as having at least one record in any state by LACs versus the number of subjects identified as having at least one record in any state by the NDR. Unlike the analysis for Table 4, for 
this part of the study, it did not matter whether the NDR identified subjects in the same states as those where LACs were conducted, nor whether LACs were conducted in a given state. Where Table 4 presents the comparison of NDR and LACs for states where investigators knew to conduct LACs, Table 5 shows how the NDR compares to LACs in identifying subjects as having at least one significant driving record, regardless of where it was incurred.

Based on the higher proportion of all offenders identified by NDR checks relative to the proportion observed in Table 4, the results from Table 5 show that NDR checks identify many subjects with significant driving records in states where investigators did not know to conduct record checks. For the population in the study, using both LACs and the NDR, 42,053 subjects would have been identified as having at least one significant driving record in at least one state. Of these 42,053 subjects, $84.3 \%(n=35,439)$ would have been identified by NDR checks versus only $31.0 \%(n=13,049)$ by LACs. Breakdowns of subjects identified by LACs and the NDR for the sample and population within the different conditions in the study (any criminal offense, any driving offense, and any self-report) are provided in Appendix E.

Table 5

Comparison of Number of Subjects Identified by LACs and NDR Checks Regardless of Where LACs Were Conducted

\begin{tabular}{lrr}
\hline & Sample & Population \\
\hline Total number identified by LACs & 4,159 & 13,049 \\
Total number identified by NDR & 5,538 & 35,439 \\
Total number identified in common & 2,056 & 6,435 \\
Total number identified by LACs \& NDR combined & 7,641 & 42,053 \\
Pct. of combined total identified by LACs & 54.4 & 31.0 \\
Pct. of combined total identified by NDR & 72.5 & 84.3 \\
\hline
\end{tabular}

\section{Distribution of Types of Offenses in the NDR for the Sample}

Table 6 presents the distribution of offenses that are indexed with the NHTSA for 5,538 subjects with NDR records in the sample. With 27,702 total offenses in the sample, each individual has an average of 27,702/5,538 or 5 convictions. As mentioned in section one, only certain offenses trigger reporting to the NDR; these have been bolded in Table 6. They reflect offenses that are either specifically required to be reported to the NDR or are of a nature likely to lead to withdrawal of driving licenses, which would then have to be reported to the NDR. The nonbolded offenses are additional factors that may have accompanied a more serious conviction or contributed to withdrawal of license to drive. 


\section{Discussion and Recommendations}

This study has shown that the NDR has good potential for identifying significant driving-related derogatory information that should be available to adjudicators and decisionmakers when making determinations about whether to place or retain individuals in positions of trust. Without the NDR, investigators currently may be failing to identify three-fourths of the subjects with significant driving problems. The NDR data will help counteract vulnerabilities present when investigators fail to check record systems in locations where offenses occur and when overlooking subjects who have not been forthcoming about negative information in their backgrounds.

Table 6

Offenses Indexed in the NDR for the Sample

\begin{tabular}{lrr}
\hline Offense & \multicolumn{1}{c}{$n$} & \multicolumn{1}{c}{$\%$} \\
\hline Speeding & 10,346 & 37.3 \\
Invalid license & $\mathbf{3 , 0 7 1}$ & $\mathbf{1 1 . 1}$ \\
Alcohol & $\mathbf{2 , 0 4 9}$ & $\mathbf{7 . 4}$ \\
Failure to obey & 1,806 & 6.5 \\
Equipment issue & 1,661 & 6.0 \\
Failure to appear & $\mathbf{1 , 3 0 1}$ & $\mathbf{4 . 7}$ \\
Reckless & $\mathbf{1 , 2 3 8}$ & $\mathbf{4 . 5}$ \\
Alcohol or drugs & $\mathbf{1 , 2 0 7}$ & $\mathbf{4 . 4}$ \\
No insurance & $\mathbf{1 , 0 6 3}$ & $\mathbf{3 . 8}$ \\
Registration issue & 795 & 2.9 \\
Other documentation issue & 735 & 2.7 \\
Wrong way & 355 & 1.3 \\
Weaving & 302 & 1.1 \\
Inspection issue & 271 & 1.0 \\
Failure to yield & 263 & 0.9 \\
Tailgate & 191 & 0.7 \\
Drugs & $\mathbf{1 7 0}$ & $\mathbf{0 . 6}$ \\
Failure to pay & 167 & 0.6 \\
Passing & 150 & 0.5 \\
Signals & 131 & 0.5 \\
Hit \& run & $\mathbf{1 1 4}$ & $\mathbf{0 . 4}$ \\
Violate restrictions & 87 & 0.3 \\
Other & 86 & 0.3 \\
Parking issue & 44 & 0.2 \\
Identity fraud & $\mathbf{3 9}$ & $\mathbf{0 . 1}$ \\
Evading & 30 & 0.1 \\
Litter & 11 & 0.0 \\
Other crime & 9 & 0.0 \\
Vehicular assault & $\mathbf{4}$ & $\mathbf{0 . 0}$ \\
Felony & $\mathbf{2}$ & $\mathbf{0 . 0}$ \\
Misdemeanor & $\mathbf{2}$ & $\mathbf{0 . 0}$ \\
Child support & 1 & 0.0 \\
Habitual offender & 1 & 0.0 \\
\hline Total & 27,702 & 100.0 \\
\hline & &
\end{tabular}


Furthermore, the NDR alone appears to be more effective (not to mention efficient) in identifying individuals with potentially significant driving-related derogatory information than existing procedures for conducting LACs. Once NDR checks are operational, ongoing research should be conducted to determine whether NDR checks could reliably replace time-consuming and potentially less effective and more costly local and state agency checks when those checks are conducted for the sole purpose of investigating driving records. As Buck (2004) showed, in some states such as Vermont and Iowa, investigators are checking state departments of transportation or motor vehicles in addition to criminal repositories. Use of the NDR could replace these checks and improve coverage by adding checks for the same individuals for every state in the country. At the same time, caution should be used in supplanting local and state agency checks with National Driver checks since results from this study showed that the NDR failed to identify a significant percentage of cases identified by local and state agency checks.

Finally, the NDR checks can be conducted through a fully automated process for all subjects. When the NDR has a record indexed for an individual, investigators would still need to follow up with the respective state to obtain details about the particular offense(s). Follow-up record checks would only need to be conducted, however, on $10 \%$ to $15 \%$ of the population. While some of the follow-up record checks would require manual processing, many could be conducted through electronic queries, depending on individual states’ capabilities.

PERSEREC and the NHTSA should initiate meetings to develop the policies, procedures, and automated system linkages needed to implement electronic NDR checks for use in federal personnel security background screening. 


\section{References}

Buck, K.R. (2004). Comparative productivity of criminal record checks by federal investigators and contracts. (Tech. Rep. 05-3). Monterey, CA: Defense Personnel Security Research Center.

Buck, K.R., \& Rose, A.E. (2004). Crime self reporting study: Phase I. (Tech. Rep. 05-1). Monterey, CA: Defense Personnel Security Research Center.

Buck, K. R., \& Reed F. M. (2003). Reliability of centralized criminal record repository checks in lieu of local criminal justice agency checks in four U.S. states: California, Florida, Pennsylvania, and Indiana with F. Michael Reed. (Tech. Rep. 03-1). Monterey, CA: Defense Personnel Security Research Center.

Federal Register: March 31, 2004 (Volume 69, Number 62) re: National Highway Traffic Safety Administration, 23 CFR 1327, Docket No. NHTSA-04-17326] RIN 2127AI45, Procedures for participating in and receiving data from the National Driver Register Problem Driver Pointer System. 
Appendix A

NDR for Cause Withdrawal and Conviction Codes 
A-2 


\section{NDR for Cause Withdrawal and Conviction Codes}

The National Driver Register Problem Driver Pointer System uses the set of codes created by the American Association of Motor Vehicle Administrators (AAMVA) for the exchange of conviction and withdrawal information between States. These codes are known as the AAMVA Code Dictionary (ACD). The list of codes and their descriptions follows.

Table A-1

NDR For Cause Withdrawal and Conviction Codes

\begin{tabular}{|c|c|}
\hline A04 & Driving under the influence of alcohol with BAC at or over .04 \\
\hline A08 & Driving under the influence of alcohol with BAC at or over .08 \\
\hline A10 & Driving under the influence of alcohol with BAC at or over .10 \\
\hline A11 & Driving under the influence of alcohol with BAC at or over _ _(detail field required) \\
\hline A12 & Refused to submit to test for alcohol - Implied Consent Law \\
\hline A20 & Driving under the influence of alcohol or drugs \\
\hline A21 & Driving under the influence of alcohol \\
\hline A22 & Driving under the influence of drugs \\
\hline A23 & Driving under the influence of alcohol and drugs \\
\hline A24 & Driving under the influence of medication not intended to intoxicate \\
\hline A25 & Driving while impaired - ability definitely impaired \\
\hline A26 & Drinking alcohol while operating a vehicle \\
\hline A27 & Driving after drinking - level of intoxication or impairment not known \\
\hline A30 & Possession \\
\hline A31 & Illegal possession of alcohol \\
\hline A32 & Illegal possession of alcohol or drugs \\
\hline A33 & Illegal possession of drugs (controlled substances) \\
\hline A34 & Illegal possession of weapon including firearm \\
\hline A35 & Possession of open alcohol container \\
\hline A40 & Aiding in violation of ignition interlock or immobilization device \\
\hline A41 & Driver violation of ignition interlock or immobilization device \\
\hline A50 & $\begin{array}{l}\text { Motor vehicle used in the manufacturing, distributing, or dispensing a controlled } \\
\text { substance }\end{array}$ \\
\hline A51 & Transporting liquor illegally \\
\hline A52 & Transporting liquor to a minor \\
\hline A60 & Underage Convicted of Drinking and Driving at .02 or higher BAC \\
\hline A61 & Underage Administrative Per Se - Drinking and Driving at .02 or higher BAC \\
\hline A90 & Administrative Per Se for .10 BAC \\
\hline A94 & Administrative Per Se for .04 BAC \\
\hline A98 & Administrative Per Se for .08 BAC \\
\hline B01 & Hit and run - failure to stop and render aid after accident \\
\hline B02 & Hit and run - failure to stop and render aid after accident - Fatal accident \\
\hline B03 & Hit and run - failure to stop and render aid after accident - Personal injury accident \\
\hline B04 & Hit and run - failure to stop and render aid after accident - Property damage accident \\
\hline
\end{tabular}




\begin{tabular}{|c|c|}
\hline B05 & Leaving accident scene before police arrive \\
\hline B06 & Leaving accident scene before police arrive - Fatal accident \\
\hline B07 & $\begin{array}{l}\text { Leaving accident scene before police arrive - Personal injury accident } \\
\end{array}$ \\
\hline B08 & Leaving accident scene before police arrive - Property damage accident \\
\hline B09 & Refusal to reveal identity after accident \\
\hline B10 & Refusal to reveal identity after accident - Fatal accident \\
\hline B11 & Refusal to reveal identity after accident - Personal injury accident \\
\hline B12 & Refusal to reveal identity after accident - Property damage accident \\
\hline B13 & Failure of duties upon damaging unattended vehicle or injuring animal \\
\hline B20 & Driving while license withdrawn \\
\hline B21 & Driving while license barred \\
\hline B22 & Driving while license canceled \\
\hline $\mathrm{B} 23$ & Driving while license denied \\
\hline B24 & Driving while license disqualified \\
\hline B25 & Driving while license revoked \\
\hline B26 & Driving while license suspended \\
\hline B27 & General, driving while an out of service order is in effect. \\
\hline B28 & Driving while registration canceled \\
\hline B29 & Driving while registration suspended \\
\hline B30 & Permit unlicensed person to drive \\
\hline B40 & Possess or provide counterfeit or altered document \\
\hline B41 & $\begin{array}{l}\text { Possess or provide counterfeit or altered driver license (includes DL, CDL, and Instruction } \\
\text { Permit) or ID }\end{array}$ \\
\hline B42 & Possess or provide counterfeit or altered registration or title \\
\hline B43 & Missing, defaced, or obscured license plates \\
\hline B44 & Mutilated document \\
\hline B45 & Mutilated driver license (includes DL, CDL, and Instruction Permit) or ID \\
\hline B46 & Mutilated registration card or title \\
\hline B50 & Expired or no document (or item) which is required \\
\hline B51 & Expired or no driver license (includes DL, CDL, and Instruction Permit) \\
\hline B52 & Expired or no emissions inspection \\
\hline B53 & Expired or no license plates or decal/sticker \\
\hline B54 & Expired or no registration or title \\
\hline B55 & Expired or no vehicle safety inspection \\
\hline B60 & Failed to file document or report as required \\
\hline B61 & Failed to file accident report \\
\hline B62 & Failed to file change of address or name \\
\hline B63 & Failed to file future proof of financial responsibility \\
\hline B64 & Failed to file insurance certification \\
\hline B65 & Failed to file medical certification/disability information \\
\hline B70 & Failed to show document as required \\
\hline B71 & Failed to show certificate of weight \\
\hline B72 & Failed to show driver license (includes DL, CDL, and Instruction Permit) \\
\hline B73 & Failed to show emissions or vehicle (safety) inspection \\
\hline
\end{tabular}




\begin{tabular}{|c|c|}
\hline B74 & Failed to show insurance certification \\
\hline B75 & Failed to show operator's (driver's) $\log$ \\
\hline B76 & Failed to show registration \\
\hline B77 & $\begin{array}{l}\text { Failed to show registration, title or driver license (includes DL, CDL, and Instruction } \\
\text { Permit) }\end{array}$ \\
\hline B80 & Failed to surrender driver license (includes DL, CDL, and Instruction Permit) \\
\hline B81 & Failed to surrender driver license, registration, plates, or title \\
\hline B82 & Failed to surrender registration, plates, or title \\
\hline B83 & False report \\
\hline B84 & False report of accident \\
\hline B85 & False report of emissions inspection \\
\hline B86 & False report of odometer reading or disclosure \\
\hline B87 & False report of Operator's (driver's) log \\
\hline B88 & False report of theft \\
\hline B89 & False report of vehicle (safety) inspection \\
\hline B90 & Failed to provide or submit title transfer documents \\
\hline B91 & $\begin{array}{l}\text { Improper classification or endorsement on driver license (includes DL, CDL, and } \\
\text { Instruction Permit) }\end{array}$ \\
\hline B92 & Loan driver license (includes DL, CDL, and Instruction Permit) to another person \\
\hline B93 & Loan registration or plates to another person \\
\hline D01 & Misrepresentation of identity or other facts \\
\hline D02 & $\begin{array}{l}\text { Misrepresentation of identity or other facts on application for driver license (includes DL, } \\
\text { CDL, and Instruction Permit) }\end{array}$ \\
\hline D03 & Misrepresentation of identity or other facts on application for handicap permit/plates \\
\hline D04 & Misrepresentation of identity or other facts on application for registration or title \\
\hline D05 & Misrepresentation of identity or other facts to avoid arrest or prosecution \\
\hline D06 & Misrepresentation of identity or other facts to obtain alcohol \\
\hline D07 & Possess multiple driver licenses (includes DL, CDL, and Instruction Permit) \\
\hline $\mathrm{D} 10$ & Manufacture or make false driver license (includes DL, CDL, and Instruction Permit) \\
\hline D11 & Manufacture or make false emissions or vehicle (safety) inspection certificates \\
\hline D12 & Manufacture or make false registration or title \\
\hline D15 & Show or use improperly - Document (or item) not specified \\
\hline D16 & Show or use improperly - Driver license (includes DL, CDL, and Instruction Permit) \\
\hline D17 & Show or use improperly - Emissions or vehicle (safety) inspection \\
\hline D18 & Show or use improperly - Insurance certification \\
\hline D19 & Show or use improperly - Operator's (driver's) log \\
\hline D20 & Show or use improperly - Registration, plates, or decal/sticker \\
\hline D21 & Show or use improperly - Registration or title \\
\hline $\mathrm{D} 25$ & Use another's driver license (includes DL, CDL, and Instruction Permit) \\
\hline $\mathrm{D} 26$ & Use another's registration, plates, or title \\
\hline D27 & Violate limited license conditions \\
\hline D28 & Violate limits of registration (manufacturer, transporter, dealer, farm, antique, etc.) \\
\hline $\mathrm{D} 29$ & Violate restrictions of driver license (includes DL, CDL, and Instruction Permit) \\
\hline D35 & Failure to comply with financial responsibility law \\
\hline
\end{tabular}




\begin{tabular}{|c|c|}
\hline D36 & Failure to maintain required liability insurance \\
\hline D37 & Failure to pay for damages or make installment payment \\
\hline D38 & Failure to post security or obtain release from liability \\
\hline D39 & Unsatisfied judgment \\
\hline $\mathrm{D} 40$ & Failure to appear \\
\hline D41 & Failure to appear for hearing or mandatory appearance \\
\hline $\mathrm{D} 42$ & Failure to appear for or complete department investigations \\
\hline D43 & Failure to appear for or complete exam/re-exam \\
\hline D44 & Failure to appear for or complete required courses \\
\hline D45 & Failure to appear for trial or court appearance. \\
\hline D50 & Failure to make required payment. \\
\hline D51 & Failure to make required payment of child support \\
\hline D52 & Failure to make required payment of fee \\
\hline D53 & Failure to make required payment of fine and costs \\
\hline D54 & Failure to make required payment of tax \\
\hline D55 & Failure to make required payment of toll \\
\hline D65 & Depositing harmful (including injurious and burning) substance on traffic way \\
\hline D66 & Failure to remove harmful substance from traffic way \\
\hline D67 & Littering from a motor vehicle \\
\hline D68 & Throwing from vehicle any harmful substance \\
\hline D70 & Driver's view obstructed \\
\hline D71 & Exceeding hours on duty limitations \\
\hline D72 & Inability to control vehicle \\
\hline D73 & $\begin{array}{l}\text { Obscuring, tampering with, or illegally displaying traffic control devices, warning, or } \\
\text { instructions }\end{array}$ \\
\hline D74 & Operating a motor vehicle improperly because of drowsiness \\
\hline D75 & Operating a motor vehicle improperly due to physical or mental disability \\
\hline D76 & Perjury \\
\hline D77 & Sex offense in a motor vehicle \\
\hline E01 & Operating without equipment as required by law \\
\hline E02 & Operating without brakes as required by law \\
\hline E03 & Operating without HAZMAT safety equipment as required by law \\
\hline E04 & Operating without HAZMAT placards/markings as required by law \\
\hline E05 & Operating without lights as required by law \\
\hline E06 & Operating without school bus equipment as required by law \\
\hline E20 & Use of equipment prohibited by law \\
\hline E21 & Use of colored lights and/or siren prohibited by law \\
\hline E22 & Use of emergency vehicle markings prohibited by law \\
\hline E23 & Use of radar or laser detector prohibited by law \\
\hline E24 & Use of vehicle lights prohibited by law \\
\hline E30 & Defective equipment \\
\hline E31 & Defective brakes \\
\hline E32 & Defective emissions control device \\
\hline E33 & Defective HAZMAT safety devices \\
\hline
\end{tabular}




\begin{tabular}{|c|c|}
\hline E34 & Defective lights \\
\hline E35 & Defective or noisy exhaust system or muffler \\
\hline E36 & Defective school bus equipment \\
\hline E37 & Defective tires \\
\hline E50 & Failure to use equipment as required \\
\hline E51 & Failure to use brakes \\
\hline$\overline{\mathrm{E} 52}$ & Failure to use disabled vehicle lights, reflectors, or flares as required \\
\hline E53 & Failure to use HAZMAT safety devices as required \\
\hline E54 & Failure to use headlight dimmer as required \\
\hline E55 & Failure to use lights as required \\
\hline E56 & Failure to use school bus safety equipment as required \\
\hline E57 & Failure to use snow tires or chains as required \\
\hline E70 & Equipment used improperly or obstructed \\
\hline E71 & Brakes used improperly \\
\hline E72 & Emissions control device used improperly or obstructed \\
\hline E73 & Equipment used improperly - making excessive noise \\
\hline E74 & Exhaust system used improperly or obstructed \\
\hline E80 & Failure to correct defects after inspection failure or notice \\
\hline F01 & Safety equipment not used properly as required \\
\hline $\mathrm{F} 02$ & Child or youth restraint not used properly as required \\
\hline F03 & Motorcycle safety equipment not used properly as required \\
\hline F04 & Seat belt not used properly as required \\
\hline F05 & Carrying unsecured passengers in open area of vehicle \\
\hline F06 & Improper operation of or riding on a motorcycle \\
\hline F10 & Exceeding or violating size, weight, or passenger/cargo limits \\
\hline F11 & Exceeding or violating passenger or cargo limits of vehicle/truck \\
\hline F12 & Exceeding or violating size limits of vehicle/truck \\
\hline F13 & Exceeding or violating weight limits of vehicle/truck \\
\hline F14 & Exceeding or violating passenger or cargo limits of motorcycle \\
\hline F15 & Exceeding or violating size limits of road/bridge/tunnel \\
\hline F16 & Exceeding or violating weight limits of road/bridge/tunnel \\
\hline F20 & Failure to weigh vehicle or stop at weigh station \\
\hline F21 & No or improper trip permit \\
\hline F22 & No warning for projecting load \\
\hline F23 & Spilling, dragging, unsecured or unsafe load \\
\hline F24 & Violation of excess size/weight permit \\
\hline F30 & Failure to place red flags or flares \\
\hline F31 & Failure to set brake(s) \\
\hline F32 & Non emergency stop \\
\hline F33 & Parking in a handicap zone \\
\hline F34 & Stopping, standing, or parking: obstructing or impeding traffic \\
\hline F35 & Stopping, standing, or parking where prohibited or improper \\
\hline F40 & Improper vehicle used on roadway \\
\hline F41 & Operate or permit vehicle where prohibited or not authorized \\
\hline
\end{tabular}




\begin{tabular}{|c|c|}
\hline F60 & Abandoned vehicle \\
\hline F61 & Alteration of emissions control device \\
\hline$\overline{\mathrm{F} 62}$ & Failed to get VIN \\
\hline F63 & Leaving vehicle unattended with engine running \\
\hline F64 & Opening vehicle door into moving traffic or while vehicle is in motion \\
\hline F65 & Towing or pushing vehicle improperly \\
\hline F66 & Unsafe condition of vehicle (no specified component) \\
\hline M01 & Failure to obey \\
\hline M02 & Failure to obey barrier \\
\hline M03 & Failure to obey construction or maintenance zone markers \\
\hline M04 & Failure to obey flagger \\
\hline M05 & Failure to obey lane markings or signal \\
\hline M06 & Failure to obey motor carrier rules/regulations \\
\hline M07 & Failure to obey pedestrian control device \\
\hline M08 & Failure to obey police or peace officer \\
\hline M09 & Failure to obey railroad crossing restrictions \\
\hline M10 & $\begin{array}{l}\text { For all drivers, failure to obey a traffic control device or the directions of an enforcement } \\
\text { official at a railroad-highway grade crossing. }\end{array}$ \\
\hline M11 & Failure to obey restricted lane \\
\hline M12 & Failure to obey safety zone \\
\hline M13 & Failure to obey school crossing guard \\
\hline M14 & Failure to obey sign or traffic control device \\
\hline M15 & Failure to obey stop sign \\
\hline M16 & Failure to obey traffic signal or light \\
\hline M17 & Failure to obey traffic sign \\
\hline M18 & Failure to obey warning light or flasher \\
\hline M19 & Failure to obey yield sign \\
\hline M20 & $\begin{array}{l}\text { For drivers who are not required to always stop, failure to slow down at a railroad- } \\
\text { highway grade crossing and check that tracks are clear of approaching train. }\end{array}$ \\
\hline M21 & $\begin{array}{l}\text { For drivers who are not required to always stop, failure to stop before reaching tracks at a } \\
\text { railroad-highway grade crossing when the tracks are not clear. }\end{array}$ \\
\hline M22 & $\begin{array}{l}\text { For drivers who are always required to stop, failure to stop as required before driving } \\
\text { onto railroad-highway grade crossing. }\end{array}$ \\
\hline M23 & $\begin{array}{l}\text { For all drivers, failing to have sufficient space to drive completely through the railroad- } \\
\text { highway grade crossing without stopping. }\end{array}$ \\
\hline M24 & $\begin{array}{l}\text { For all drivers, failing to negotiate a railroad-highway grade crossing because of } \\
\text { insufficient undercarriage clearance. }\end{array}$ \\
\hline M25 & $\begin{array}{l}\text { Failure to stop - basic rule at unsigned intersection or when entering roadway from private } \\
\text { driveway, alley, etc. }\end{array}$ \\
\hline M30 & Following improperly \\
\hline M31 & Failure to leave sufficient distance for overtaking by other vehicles \\
\hline M32 & Following emergency vehicle unlawfully \\
\hline M33 & Following fire equipment unlawfully \\
\hline M34 & Following too closely \\
\hline
\end{tabular}




\begin{tabular}{|c|c|}
\hline M40 & Improper lane or location \\
\hline M41 & Failure to keep in proper lane \\
\hline M42 & Improper or erratic (unsafe) lane changes \\
\hline M43 & Ran off road \\
\hline M44 & Improper lane or location - crossover \\
\hline M45 & Improper lane or location - crosswalk \\
\hline M46 & Improper lane or location - entrance/exit ramp or way \\
\hline M47 & Improper lane or location - in bicycle lane \\
\hline M48 & Improper lane or location - in occupied lane \\
\hline M49 & Improper lane or location - in HOV or restricted lane \\
\hline M50 & Improper lane or location - limited access highway \\
\hline M51 & Improper lane or location - median \\
\hline M52 & Improper lane or location - not on National Network \\
\hline M53 & Improper lane or location - not on route authorized by permit \\
\hline M54 & Improper lane or location - not on truck route \\
\hline M55 & Improper lane or location - on rail or streetcar tracks \\
\hline M56 & Improper lane or location - on fire hose \\
\hline M57 & Improper lane or location - oncoming traffic lane \\
\hline M58 & Improper lane or location - road shoulder, ditch or sidewalk \\
\hline M60 & Improper lane or location - slower vehicle lane \\
\hline M61 & Improper lane or location - straddling center line(s) \\
\hline M62 & Improper lane or location - traveling in turn (or center) lane \\
\hline M70 & Improper passing \\
\hline M71 & Passing in violation of posted sign or pavement marking \\
\hline M72 & Passing in violation of opposite directions restriction \\
\hline M73 & Passing on wrong side \\
\hline M74 & Passing on hill or curve \\
\hline M75 & Passing school bus displaying warning not to pass \\
\hline M76 & Passing where prohibited \\
\hline M77 & Passing with insufficient distance or visibility \\
\hline M80 & Reckless, careless, or negligent driving \\
\hline M81 & Careless driving \\
\hline M82 & Inattentive driving \\
\hline M83 & Negligent driving \\
\hline M84 & Reckless driving \\
\hline N01 & Failure to yield right of way (FTY ROW) \\
\hline N02 & FTY ROW to animal rider or animal-drawn vehicle \\
\hline N03 & FTY ROW to cyclist \\
\hline N04 & FTY ROW to emergency vehicle (i.e. ambulance, fire equipment, police, etc.) \\
\hline N05 & FTY ROW to funeral procession, procession or parade \\
\hline N06 & FTY ROW to other vehicle \\
\hline N07 & FTY ROW to overtaking vehicle \\
\hline N08 & FTY ROW to pedestrian (includes handicapped or blind) \\
\hline N09 & FTY ROW to school bus \\
\hline
\end{tabular}




\begin{tabular}{|c|c|}
\hline $\mathrm{N} 20$ & FTY ROW at crosswalk \\
\hline N21 & FTY ROW at rotary \\
\hline N22 & FTY ROW at stop sign \\
\hline $\mathrm{N} 23$ & FTY ROW at traffic sign \\
\hline N24 & FTY ROW at traffic signal \\
\hline N25 & FTY ROW at unsigned intersection \\
\hline N26 & FTY ROW at yield sign \\
\hline N30 & FTY ROW when warning displayed on other vehicle \\
\hline N31 & FTY ROW when turning \\
\hline N40 & Failure to use or improper signal \\
\hline N41 & Failure to cancel directional signals \\
\hline N42 & Failure to signal intention to pass \\
\hline N43 & Failure to signal lane change or turn \\
\hline N44 & Giving wrong signal \\
\hline N50 & Improper turn \\
\hline N51 & Improper method of turning \\
\hline N52 & Improper position for turning \\
\hline N53 & Making improper left turn \\
\hline N54 & Making improper right turn \\
\hline N55 & Making improper turn around (not U turn) \\
\hline N56 & Making improper U turn \\
\hline N60 & Driving wrong way \\
\hline N61 & Driving wrong way at rotary intersection \\
\hline N62 & Driving wrong way on divided highway \\
\hline N63 & Driving wrong way on one way street or road \\
\hline N70 & Driving on wrong side \\
\hline N71 & Driving on wrong side of divided highway \\
\hline N72 & Driving on wrong side of undivided street or road \\
\hline N80 & Coasting (operating with gears disengaged) \\
\hline N81 & Clinging to other vehicles \\
\hline N82 & Improper backing \\
\hline N83 & Improper starting \\
\hline N84 & Unsafe operation \\
\hline S01 & 01-05 > Speed limit (detail optional) \\
\hline S06 & 06-10 > Speed limit (detail optional) \\
\hline S11 & 11-15 > Speed limit (detail optional) \\
\hline S15 & Speeding $15 \mathrm{mph}$ or more above speed limit (detail optional) \\
\hline S16 & $16-20>$ Speed limit (detail optional) \\
\hline S21 & 21-25 > Speed limit (detail optional) \\
\hline S26 & 26-30 > Speed limit (detail optional) \\
\hline S31 & 31-35 > Speed limit (detail optional) \\
\hline & 36-40 > Speed limit (detail optional) \\
\hline S41 & $41+\quad>$ Speed limit (detail optional) \\
\hline S50 & Speeding in a school zone (detail optional) \\
\hline
\end{tabular}




\begin{tabular}{|c|c|}
\hline S51 & $01-10>$ Speed limit (detail optional) \\
\hline S61 & 11-20 > Speed limit (detail optional) \\
\hline S71 & 21-30 > Speed limit (detail optional) \\
\hline S81 & 31-40 > Speed limit (detail optional) \\
\hline S91 & $41+\quad>$ Speed limit (detail optional) \\
\hline S92 & Speeding - Speed limit and actual speed (detail required) \\
\hline S93 & Speeding \\
\hline S94 & Prima Facie speed violation or driving too fast for conditions \\
\hline S95 & Speed contest (racing) on road open to traffic \\
\hline S96 & Speed less than minimum \\
\hline S97 & Operating at erratic or suddenly changing speeds \\
\hline S98 & Speeding on freeway ("wasting fuel") \\
\hline S99 & Speeding in a school zone \\
\hline $\mathrm{U} 01$ & Fleeing or evading police or roadblock \\
\hline U02 & Resisting arrest \\
\hline $\mathrm{U} 03$ & Using a motor vehicle in connection with a felony (not traffic offense) \\
\hline U04 & Using a motor vehicle in connection with a misdemeanor (not traffic offense) \\
\hline U05 & Using a motor vehicle to aid and abet a felon \\
\hline U06 & Vehicular assault \\
\hline U07 & Vehicular homicide \\
\hline U08 & Vehicular manslaughter \\
\hline $\mathrm{U} 20$ & Damaging or tampering with vehicle \\
\hline $\mathrm{U} 21$ & Illegal operation of emergency vehicle \\
\hline $\mathrm{U} 22$ & Odometer tampering \\
\hline $\mathrm{U} 23$ & Receiving or disposing of stolen vehicle or its parts \\
\hline $\mathrm{U} 24$ & Removal, falsification, or unauthorized use of VIN on registration plate \\
\hline $\mathrm{U} 25$ & Unauthorized use of a vehicle or taking a vehicle without owner consent \\
\hline $\mathrm{U} 26$ & Vehicle theft \\
\hline $\mathrm{U} 30$ & Violation resulting in accident \\
\hline U31 & Violation resulting in fatal accident \\
\hline $\mathrm{U} 32$ & Violation resulting in personal injury accident \\
\hline U33 & Violation resulting in property damage accident \\
\hline W01 & $\begin{array}{l}\text { Accumulation of convictions (including point systems and/or being judged a habitual } \\
\text { offender or violator) }\end{array}$ \\
\hline W10 & Withdrawal (reason not specified) \\
\hline W11 & Family report recommended \\
\hline W12 & Immigration law offender \\
\hline W13 & Parental consent withdrawn \\
\hline W14 & Physical or mental disability \\
\hline W15 & Physicians' or specialists' report recommended \\
\hline W20 & Unable to pass DL test(s) or meet qualifications \\
\hline W21 & Unable to pass re-examination \\
\hline W22 & Under age for license \\
\hline W23 & Under age possession of tobacco \\
\hline
\end{tabular}




\begin{tabular}{|ll|}
\hline W24 & Under age school dropout \\
\hline W25 & Disobeying terms of probation \\
\hline W26 & Insufficient funds, protested or invalid check \\
\hline W30 & Two serious violations within 3 years \\
\hline W31 & Three serious violations within 3 years \\
\hline W60 & The accumulation of two RRGC violations within 3 years \\
\hline W61 & The accumulation of three or more RRGC violations within 3 years \\
\hline
\end{tabular}


Appendix B

Method of Coding Records Checks

B-1 
B-2 


\section{Method of Coding Records Checks}

When records are located, investigators describe the content therein. The amount of information available to them varies. For example, dispositions of arrests, to include convictions and terms of sentencing, are not always apparent, and the levels of offenses (e.g., infraction, misdemeanor, felony) are not always noted. Nonetheless, it is clear from their reports when investigators have found some kind of information from an agency for a given subject. Typical examples of ROIs that describe records that are found are as follows²:

1. A review of the records of the X County Sheriff's Office (LCSO) and the X County Criminal Courts (LCCC), City, State, servicing City and City, State regarding SUBJECT disclosed information pertaining to her Criminal Conduct. CRIMINAL CONDUCT Arrest: LCCC files disclosed that in 19XX, SUBJECT was arrested and charged with dealing in stolen property, a felony offense. This case was filed under LCCC felony division case file \# $\mathrm{xx}-\mathrm{xxx}-\mathrm{xx}-\mathrm{x}-\mathrm{xx}$. A review of both LCSO and LCCC files failed to locate any arrest/incident report detailing this arrest. Disposition: On X Sep XX, the LCCC remanded the above felony level case down to a misdemeanor, case file \# xx-xxxx-xxx-xx, Attachment 1 pertains. Due to the passage of time, the case file was destroyed in 1993 per LCCC policy. Available record information reflected that on X Sep XX, the case was remanded down to a misdemeanor and on X Oct XX, SUBJECT entered into a pre-trial agreement. On xx Oct XX, the case was dismissed in X County Court, Attachment 2 pertains. (13 Feb 02)

2. Records of the Vallejo, CA Police Department disclosed that on XX April XX, SUBJECT was arrested for Driving While Intoxicated (DWI), a misdemeanor and Speeding. (5 Dec 01)

3. Records of the Crime Information Center, Georgia Bureau of Investigation, Decatur, GA, servicing all locations in the State of Georgia, revealed SUBJECT was arrested on X Aug XX by the Atlanta Police Department for Affray (fighting). (15 Nov 01)

Figure B-1 Example of Reports of Investigation When Criminal Records Are Found.

\footnotetext{
${ }^{2}$ Information that could reveal or enable determination of personally identifying information has been removed to protect the privacy of the subjects.
} 
In reports of criminal record checks where no records are found, investigators simply list the agency checked or explicitly mention that no records are found. Typical examples of ROIs where information is not found are listed in Figure B-2. ${ }^{3}$

1. Records on file with the Yuma County Justice Court First Precinct (YCJCFP), Yuma, AZ, servicing the City of Yuma, AZ and surrounding area, were reviewed and disclosed no information identifiable with Subject. [1817](11 Feb 02)

2. Pima County Sheriff's Office, Tucson, AZ. (1 Feb 02)

3. Records of the Baltimore City Police Department (BCPD), Baltimore, MD, disclosed no information pertaining to SUBJECT and the listed XX Oct XX charge of Driving While Intoxicated. BCPD files do not contain arrest for Driving While Intoxicated offenses. BCPD files disclosed no additional information. (28 Jan 02)

Figure B-2 Example of Reports of Investigation When Criminal Records Are Not Found.

${ }^{3}$ Personally identifying information about subjects has been removed to protect the privacy of the subjects. 


\section{Appendix C}

Complete Statistical Match Results and Analysis, Record Level, By State 


$$
\text { C-2 }
$$


Table C-1

Complete Statistical Match Results and Analysis, Record Level

\begin{tabular}{rrrrrrrrrrr}
\hline & \multicolumn{10}{c}{ Sample Frequencies } \\
\cline { 2 - 11 } Any Crime & No & No & No & No & No & No & Yes & Yes & Yes \\
Any Drive & No & No & No & No & No & No & No & No & No \\
Any Self-Report & No & No & No & Yes & Yes & \multicolumn{1}{c}{ Yes } & No & No & No \\
NDR & No & Yes & Total & No & Yes & Total & No & Yes & Total \\
\hline State & AK & 146 & 4 & 150 & 137 & 13 & 150 & 11 & 2 & 13 \\
AL & 147 & 3 & 150 & 144 & 6 & 150 & 101 & 8 & 109 \\
AR & 146 & 4 & 150 & 142 & 8 & 150 & 81 & 29 & 110 \\
AZ & 146 & 4 & 150 & 133 & 17 & 150 & 103 & 24 & 127 \\
CA & 149 & 1 & 150 & 140 & 10 & 150 & 85 & 5 & 90 \\
CO & 148 & 2 & 150 & 140 & 10 & 150 & 86 & 35 & 121 \\
CT & 145 & 5 & 150 & 143 & 7 & 150 & 124 & 17 & 141 \\
DC & 149 & 1 & 150 & 147 & 2 & 149 & 84 & 6 & 90 \\
DE & 148 & 2 & 150 & 147 & 2 & 149 & 129 & 2 & 131 \\
FL & 144 & 6 & 150 & 144 & 6 & 150 & 112 & 14 & 126 \\
GA & 140 & 10 & 150 & 141 & 9 & 150 & 76 & 12 & 88 \\
HI & 148 & 2 & 150 & 146 & 4 & 150 & 92 & 4 & 96 \\
IA & 140 & 10 & 150 & 139 & 11 & 150 & 51 & 13 & 64 \\
ID & 146 & 4 & 150 & 135 & 15 & 150 & 37 & 8 & 45 \\
IL & 141 & 9 & 150 & 138 & 12 & 150 & 102 & 29 & 131 \\
IN & 141 & 9 & 150 & 141 & 9 & 150 & 105 & 5 & 110 \\
KS & 146 & 3 & 149 & 147 & 3 & 150 & 50 & 8 & 58 \\
KY & 149 & 1 & 150 & 148 & 2 & 150 & 126 & 12 & 138 \\
LA & 148 & 2 & 150 & 144 & 6 & 150 & 106 & 21 & 127 \\
MA & 142 & 7 & 149 & 143 & 7 & 150 & 86 & 24 & 110 \\
MD & 149 & 1 & 150 & 147 & 3 & 150 & 47 & 11 & 58 \\
ME & 147 & 3 & 150 & 140 & 10 & 150 & 83 & 53 & 136 \\
MI & 147 & 3 & 150 & 146 & 4 & 150 & 120 & 14 & 134 \\
MN & 150 & 0 & 150 & 147 & 3 & 150 & 141 & 2 & 143 \\
MO & 149 & 1 & 150 & 141 & 9 & 150 & 101 & 12 & 113 \\
MS & 147 & 2 & 149 & 146 & 4 & 150 & 114 & 13 & 127 \\
\hline & & & & & & & & &
\end{tabular}


Table C-1 (continued)

Complete Statistical Match Results and Analysis, Record Level

\begin{tabular}{rrrrrrrrrrr}
\hline & \multicolumn{10}{c}{ Sample Frequencies } \\
\cline { 2 - 11 } Any Crime & No & No & No & No & No & No & Yes & Yes & \multicolumn{1}{c}{ Yes } \\
Any Drive & No & No & No & No & No & No & No & No & No \\
Any Self-Report & No & No & No & Yes & Yes & Yes & No & No & \multicolumn{1}{c}{ No } \\
NDR & No & Yes & Total & \multicolumn{1}{c}{ No } & Yes & Total & No & Yes & Total \\
\hline State & MT & 149 & 1 & 150 & 145 & 5 & 150 & 25 & 5 & 30 \\
NC & 138 & 11 & 149 & 135 & 15 & 150 & 105 & 19 & 124 \\
ND & 148 & 2 & 150 & 146 & 4 & 150 & 37 & 10 & 47 \\
NE & 148 & 2 & 150 & 149 & 1 & 150 & 44 & 7 & 51 \\
NH & 145 & 5 & 150 & 142 & 7 & 149 & 71 & 31 & 102 \\
NJ & 146 & 3 & 149 & 143 & 7 & 150 & 125 & 3 & 128 \\
NM & 148 & 2 & 150 & 148 & 2 & 150 & 124 & 9 & 133 \\
NV & 149 & 1 & 150 & 143 & 7 & 150 & 34 & 6 & 40 \\
NY & 145 & 4 & 149 & 143 & 6 & 149 & 109 & 11 & 120 \\
OH & 144 & 6 & 150 & 133 & 17 & 150 & 92 & 23 & 115 \\
OK & 144 & 5 & 149 & 144 & 6 & 150 & 97 & 24 & 121 \\
OR & 135 & 15 & 150 & 122 & 28 & 150 & 42 & 14 & 56 \\
PA & 146 & 3 & 149 & 142 & 8 & 150 & 101 & 20 & 121 \\
PR & 150 & 0 & 150 & 150 & 0 & 150 & 16 & 0 & 16 \\
RI & 143 & 7 & 150 & 141 & 9 & 150 & 42 & 4 & 46 \\
SC & 146 & 4 & 150 & 144 & 6 & 150 & 110 & 18 & 128 \\
SD & 142 & 8 & 150 & 140 & 10 & 150 & 124 & 8 & 132 \\
TN & 143 & 6 & 149 & 139 & 11 & 150 & 40 & 4 & 44 \\
TX & 149 & 1 & 150 & 150 & 0 & 150 & 122 & 1 & 123 \\
UT & 141 & 9 & 150 & 119 & 31 & 150 & 55 & 12 & 67 \\
VA & 141 & 8 & 149 & 138 & 12 & 150 & 116 & 20 & 136 \\
VT & 147 & 3 & 150 & 84 & 2 & 86 & 110 & 10 & 120 \\
WA & 145 & 5 & 150 & 138 & 12 & 150 & 109 & 3 & 112 \\
WI & 143 & 7 & 150 & 114 & 36 & 150 & 67 & 15 & 82 \\
WV & 146 & 4 & 150 & 136 & 14 & 150 & 109 & 31 & 140 \\
WY & 146 & 4 & 150 & 146 & 4 & 150 & 6 & 2 & 8 \\
\hline Total & 7,565 & 225 & 7,790 & 7,280 & 452 & 7,732 & 4,385 & 693 & 5,078 \\
\hline
\end{tabular}


Table C-1 (continued)

Complete Statistical Match Results and Analysis, Record Level

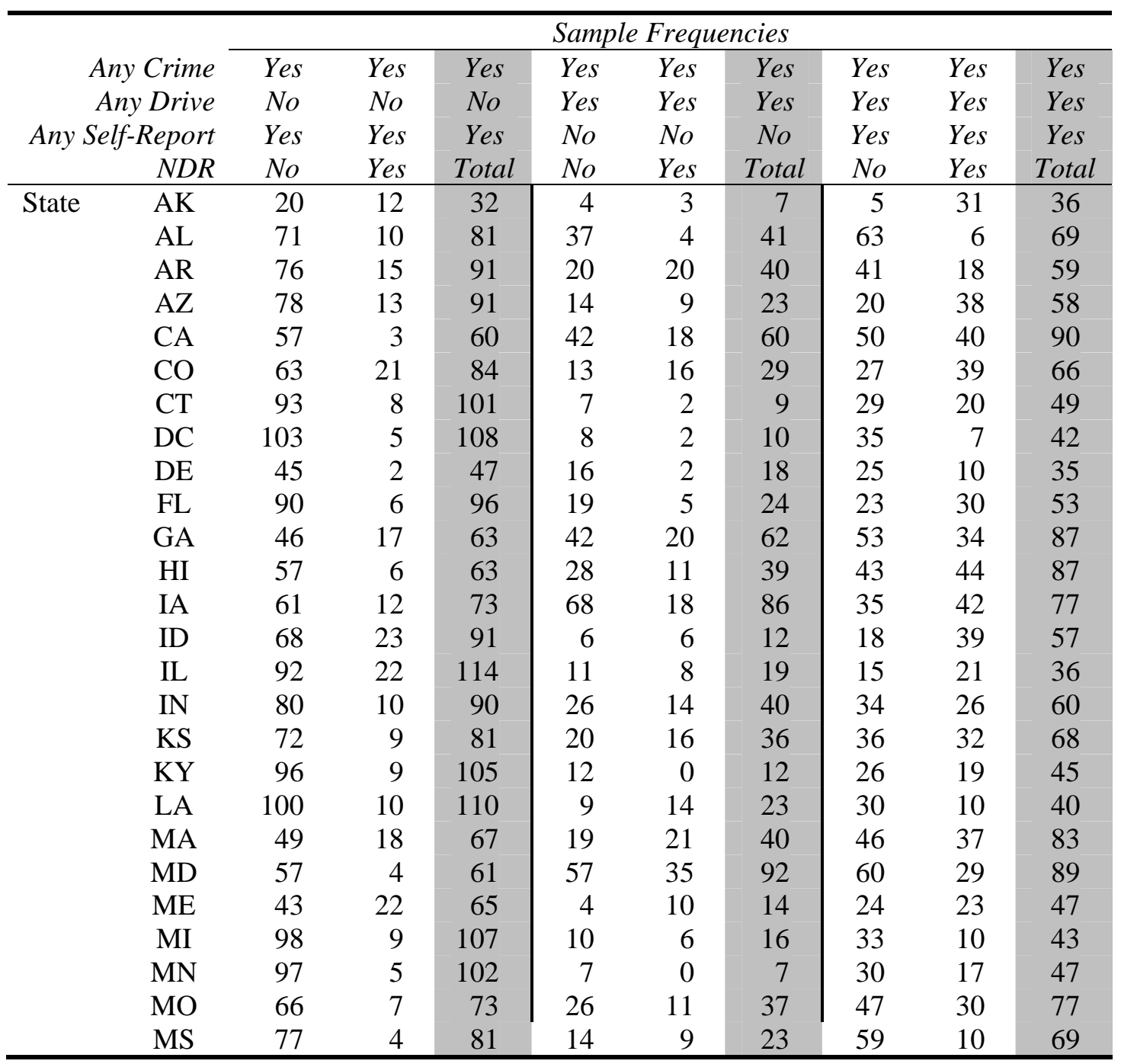


Table C-1 (continued)

Complete Statistical Match Results and Analysis, Record Level

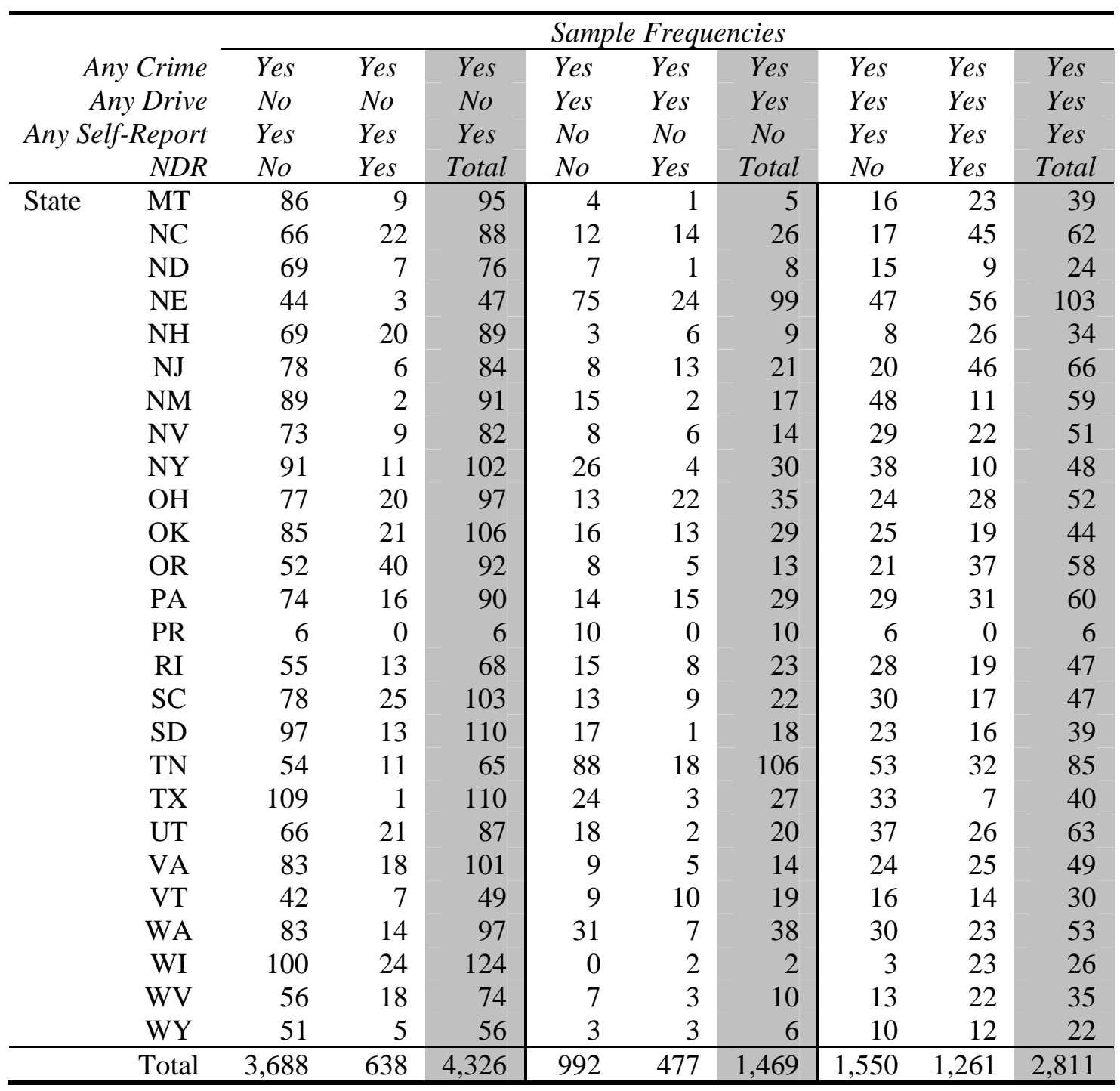


Table C-1 (continued)

Complete Statistical Match Results and Analysis, Record Level

\begin{tabular}{|c|c|c|c|c|c|c|c|}
\hline \multirow{2}{*}{\multicolumn{2}{|c|}{ Any Crime }} & \multicolumn{6}{|c|}{ Percent Identified by NDR in Sample } \\
\hline & & $\mathrm{No}$ & No & Yes & Yes & Yes & Yes \\
\hline \multicolumn{2}{|c|}{ Any Drive } & No & No & No & No & Yes & Yes \\
\hline \multicolumn{2}{|c|}{ Any Self-Report } & No & Yes & No & Yes & No & Yes \\
\hline \multirow[t]{26}{*}{ State } & AK & 2.7 & 8.7 & 15.4 & 37.5 & 42.9 & 86.1 \\
\hline & $\mathrm{AL}$ & 2.0 & 4.0 & 7.3 & 12.3 & 9.8 & 8.7 \\
\hline & AR & 2.7 & 5.3 & 26.4 & 16.5 & 50.0 & 30.5 \\
\hline & $\mathrm{AZ}$ & 2.7 & 11.3 & 18.9 & 14.3 & 39.1 & 65.5 \\
\hline & CA & 0.7 & 6.7 & 5.6 & 5.0 & 30.0 & 44.4 \\
\hline & $\mathrm{CO}$ & 1.3 & 6.7 & 28.9 & 25.0 & 55.2 & 59.1 \\
\hline & CT & 3.3 & 4.7 & 12.1 & 7.9 & 22.2 & 40.8 \\
\hline & DC & 0.7 & 1.3 & 6.7 & 4.6 & 20.0 & 16.7 \\
\hline & $\mathrm{DE}$ & 1.3 & 1.3 & 1.5 & 4.3 & 11.1 & 28.6 \\
\hline & FL & 4.0 & 4.0 & 11.1 & 6.3 & 20.8 & 56.6 \\
\hline & GA & 6.7 & 6.0 & 13.6 & 27.0 & 32.3 & 39.1 \\
\hline & HI & 1.3 & 2.7 & 4.2 & 9.5 & 28.2 & 50.6 \\
\hline & IA & 6.7 & 7.3 & 20.3 & 16.4 & 20.9 & 54.5 \\
\hline & ID & 2.7 & 10.0 & 17.8 & 25.3 & 50.0 & 68.4 \\
\hline & IL & 6.0 & 8.0 & 22.1 & 19.3 & 42.1 & 58.3 \\
\hline & IN & 6.0 & 6.0 & 4.5 & 11.1 & 35.0 & 43.3 \\
\hline & $\mathrm{KS}$ & 2.0 & 2.0 & 13.8 & 11.1 & 44.4 & 47.1 \\
\hline & KY & 0.7 & 1.3 & 8.7 & 8.6 & 0.0 & 42.2 \\
\hline & LA & 1.3 & 4.0 & 16.5 & 9.1 & 60.9 & 25.0 \\
\hline & MA & 4.7 & 4.7 & 21.8 & 26.9 & 52.5 & 44.6 \\
\hline & MD & 0.7 & 2.0 & 19.0 & 6.6 & 38.0 & 32.6 \\
\hline & $\mathrm{ME}$ & 2.0 & 6.7 & 39.0 & 33.8 & 71.4 & 48.9 \\
\hline & MI & 2.0 & 2.7 & 10.4 & 8.4 & 37.5 & 23.3 \\
\hline & MN & 0.0 & 2.0 & 1.4 & 4.9 & 0.0 & 36.2 \\
\hline & MO & 0.7 & 6.0 & 10.6 & 9.6 & 29.7 & 39.0 \\
\hline & MS & 1.3 & 2.7 & 10.2 & 4.9 & 39.1 & 14.5 \\
\hline
\end{tabular}


Table C-1 (continued)

Complete Statistical Match Results and Analysis, Record Level

\begin{tabular}{|c|c|c|c|c|c|c|c|}
\hline \multirow{2}{*}{\multicolumn{2}{|c|}{ Any Crime }} & \multicolumn{6}{|c|}{ Percent Identified by NDR in Sample } \\
\hline & & No & $\mathrm{No}$ & Yes & Yes & Yes & Yes \\
\hline & Drive & No & No & No & No & Yes & Yes \\
\hline \multicolumn{2}{|c|}{ Any Self-Report } & No & Yes & No & Yes & No & Yes \\
\hline \multirow[t]{27}{*}{ State } & $\mathrm{MT}$ & 0.7 & 3.3 & 16.7 & 9.5 & 20.0 & 59.0 \\
\hline & NC & 7.4 & 10.0 & 15.3 & 25.0 & 53.8 & 72.6 \\
\hline & ND & 1.3 & 2.7 & 21.3 & 9.2 & 12.5 & 37.5 \\
\hline & $\mathrm{NE}$ & 1.3 & 0.7 & 13.7 & 6.4 & 24.2 & 54.4 \\
\hline & $\mathrm{NH}$ & 3.3 & 4.7 & 30.4 & 22.5 & 66.7 & 76.5 \\
\hline & NJ & 2.0 & 4.7 & 2.3 & 7.1 & 61.9 & 69.7 \\
\hline & NM & 1.3 & 1.3 & 6.8 & 2.2 & 11.8 & 18.6 \\
\hline & NV & 0.7 & 4.7 & 15.0 & 11.0 & 42.9 & 43.1 \\
\hline & NY & 2.7 & 4.0 & 9.2 & 10.8 & 13.3 & 20.8 \\
\hline & $\mathrm{OH}$ & 4.0 & 11.3 & 20.0 & 20.6 & 62.9 & 53.8 \\
\hline & OK & 3.4 & 4.0 & 19.8 & 19.8 & 44.8 & 43.2 \\
\hline & OR & 10.0 & 18.7 & 25.0 & 43.5 & 38.5 & 63.8 \\
\hline & PA & 2.0 & 5.3 & 16.5 & 17.8 & 51.7 & 51.7 \\
\hline & PR & 0.0 & 0.0 & 0.0 & 0.0 & 0.0 & 0.0 \\
\hline & RI & 4.7 & 6.0 & 8.7 & 19.1 & 34.8 & 40.4 \\
\hline & SC & 2.7 & 4.0 & 14.1 & 24.3 & 40.9 & 36.2 \\
\hline & SD & 5.3 & 6.7 & 6.1 & 11.8 & 5.6 & 41.0 \\
\hline & $\mathrm{TN}$ & 4.0 & 7.3 & 9.1 & 16.9 & 17.0 & 37.6 \\
\hline & TX & 0.7 & 0.0 & 0.8 & 0.9 & 11.1 & 17.5 \\
\hline & UT & 6.0 & 20.7 & 17.9 & 24.1 & 10.0 & 41.3 \\
\hline & VA & 5.4 & 8.0 & 14.7 & 17.8 & 35.7 & 51.0 \\
\hline & VT & 2.0 & 2.3 & 8.3 & 14.3 & 52.6 & 46.7 \\
\hline & WA & 3.3 & 8.0 & 2.7 & 14.4 & 18.4 & 43.4 \\
\hline & WI & 4.7 & 24.0 & 18.3 & 19.4 & 100.0 & 88.5 \\
\hline & WV & 2.7 & 9.3 & 22.1 & 24.3 & 30.0 & 62.9 \\
\hline & WY & 2.7 & 2.7 & 25.0 & 8.9 & 50.0 & 54.5 \\
\hline & Total & 2.9 & 5.8 & 13.6 & 14.7 & 32.5 & 44.9 \\
\hline
\end{tabular}


Table C-1 (continued)

Complete Statistical Match Results and Analysis, Record Level

\begin{tabular}{cccc}
\hline Total in & $\begin{array}{c}\text { Total in } \\
\text { Population } \\
\text { wopulation } \\
\text { (includes } \\
\text { missing } \\
\text { values) }\end{array}$ & $\begin{array}{c}\text { Total in Pop. } \\
\text { NonMissing } \\
\text { Values }^{a}\end{array}$ & $\begin{array}{c}\text { With LAC } \\
\text { Driving } \\
\text { Offense }\end{array}$ \\
\hline AK & 801 & 798 & 43 \\
AL & 12,156 & 12,134 & 346 \\
AR & 3,141 & 3,137 & 145 \\
AZ & 10,266 & 10,237 & 183 \\
CA & 21,545 & 21,467 & 882 \\
CO & 9,582 & 9,536 & 271 \\
CT & 6,771 & 6,766 & 135 \\
DC & 9,273 & 9,242 & 55 \\
DE & 1,339 & 1,339 & 53 \\
FL & 26,970 & 26,905 & 698 \\
GA & 19,034 & 18,989 & 621 \\
HI & 7,850 & 7,838 & 135 \\
IA & 2,833 & 2,829 & 363 \\
ID & 1,941 & 1,934 & 69 \\
IL & 13,251 & 13,236 & 150 \\
IN & 5,658 & 5,652 & 167 \\
KS & 5,604 & 5,591 & 146 \\
KY & 5,745 & 5,736 & 201 \\
LA & 6,756 & 6,747 & 136 \\
MA & 9,249 & 9,238 & 353 \\
MD & 6,854 & 6,762 & 789 \\
ME & 1,921 & 1,915 & 62 \\
MI & 6,972 & 6,947 & 606 \\
MN & 4,713 & 4,699 & 127 \\
MO & 11,595 & 11,583 & 405 \\
MS & 4,920 & 4,916 & 113 \\
\hline
\end{tabular}

${ }^{a}$ Nonmissing values refers to cases not missing values on variables indicating any criminal activity, any driving offense, and any self-report. 
Table C-1 (continued)

Complete Statistical Match Results and Analysis, Record Level

\begin{tabular}{|c|c|c|c|}
\hline State & $\begin{array}{l}\text { Total in } \\
\text { Population } \\
\text { (includes } \\
\text { missing } \\
\text { values) }\end{array}$ & $\begin{array}{c}\text { Total in } \\
\text { Population } \\
\text { with } \\
\text { NonMissing }^{\text {Values }}{ }^{a}\end{array}$ & $\begin{array}{c}\text { Total in Pop. } \\
\text { With LAC } \\
\text { Driving } \\
\text { Offense }\end{array}$ \\
\hline MT & 1,652 & 1,649 & 44 \\
\hline NC & 17,858 & 17,746 & 821 \\
\hline ND & 1,511 & 1,511 & 32 \\
\hline $\mathrm{NE}$ & 3,519 & 3,513 & 464 \\
\hline $\mathrm{NH}$ & 2,921 & 2,918 & 43 \\
\hline NJ & 7,992 & 7,976 & 850 \\
\hline NM & 3,742 & 3,733 & 123 \\
\hline $\mathrm{NV}$ & 3,078 & 3,075 & 65 \\
\hline NY & 15,500 & 15,461 & 388 \\
\hline $\mathrm{OH}$ & 10,318 & 10,302 & 376 \\
\hline OK & 7,683 & 7,677 & 252 \\
\hline OR & 3,029 & 3,028 & 93 \\
\hline $\mathrm{PA}$ & 12,248 & 12,223 & 290 \\
\hline PR & 2,622 & 2,620 & 16 \\
\hline RI & 3,520 & 3,513 & 70 \\
\hline SC & 10,860 & 10,847 & 133 \\
\hline SD & 1,254 & 1,253 & 57 \\
\hline $\mathrm{TN}$ & 7,666 & 7,652 & 624 \\
\hline $\mathrm{TX}$ & 10,059 & 10,028 & 445 \\
\hline UT & 3,673 & 3,672 & 127 \\
\hline VA & 41,578 & 41,360 & 676 \\
\hline VT & 869 & 868 & 49 \\
\hline WA & 11,876 & 11,859 & 199 \\
\hline WI & 4,319 & 4,312 & 59 \\
\hline WV & 2,068 & 2,062 & 47 \\
\hline WY & 1,110 & 1,108 & 28 \\
\hline Total & 409,265 & 408,139 & 13,625 \\
\hline
\end{tabular}

${ }^{a}$ Nonmissing values refers to cases not missing values on variables indicating any criminal activity, any driving offense, and any self-report. 
Table C-1 (continued)

Complete Statistical Match Results and Analysis, Record Level

\begin{tabular}{rrrrrrr}
\hline & \multicolumn{6}{c}{ Total Population } \\
\cline { 2 - 7 } Any Crime & No & No & Yes & Yes & Yes & Yes \\
Any Drive & No & No & No & No & Yes & Yes \\
Any Self-Report & \multicolumn{1}{c}{ No } & \multicolumn{1}{c}{ Yes } & \multicolumn{1}{c}{ No } & Yes & \multicolumn{1}{c}{ No } & Yes \\
\hline State AK & 504 & 206 & 13 & 32 & 7 & 36 \\
AL & 9,386 & 1,832 & 254 & 316 & 92 & 254 \\
AR & 2,275 & 421 & 139 & 157 & 47 & 98 \\
AZ & 7,625 & 1,982 & 132 & 315 & 24 & 159 \\
CA & 15,363 & 4,497 & 328 & 397 & 243 & 639 \\
CO & 7,126 & 1,608 & 220 & 311 & 57 & 214 \\
CT & 5,067 & 1,127 & 174 & 263 & 13 & 122 \\
DC & 7,356 & 1,622 & 90 & 119 & 10 & 45 \\
DE & 913 & 194 & 131 & 48 & 18 & 35 \\
FL & 19,815 & 4,508 & 908 & 976 & 198 & 500 \\
GA & 14,081 & 3,587 & 295 & 405 & 166 & 455 \\
HI & 6,030 & 1,510 & 96 & 67 & 39 & 96 \\
IA & 1,807 & 358 & 129 & 172 & 176 & 187 \\
ID & 1,310 & 419 & 45 & 91 & 12 & 57 \\
IL & 10,290 & 2,247 & 202 & 347 & 29 & 121 \\
IN & 4,322 & 856 & 118 & 189 & 42 & 125 \\
KS & 4,410 & 857 & 58 & 120 & 36 & 110 \\
KY & 3,667 & 869 & 712 & 287 & 71 & 130 \\
LA & 5,028 & 1,132 & 174 & 277 & 28 & 108 \\
MA & 7,325 & 973 & 357 & 230 & 144 & 209 \\
MD & 4,389 & 1,053 & 169 & 362 & 263 & 526 \\
ME & 1,340 & 299 & 149 & 65 & 15 & 47 \\
MI & 2,863 & 394 & 2,103 & 981 & 209 & 397 \\
MN & 3,280 & 643 & 383 & 266 & 24 & 103 \\
MO & 8,854 & 1,587 & 344 & 393 & 99 & 306 \\
MS & 3,721 & 826 & 143 & 113 & 29 & 84 \\
\hline
\end{tabular}


Table C-1 (continued)

Complete Statistical Match Results and Analysis, Record Level

\begin{tabular}{|c|c|c|c|c|c|c|}
\hline \multirow[b]{2}{*}{ Any Crime } & \multicolumn{6}{|c|}{ Total Population } \\
\hline & No & No & Yes & Yes & Yes & Yes \\
\hline Any Drive & No & No & No & No & Yes & Yes \\
\hline Any Self-Report & No & Yes & No & Yes & No & Yes \\
\hline State $\quad$ MT & 1,251 & 229 & 30 & 95 & 5 & 39 \\
\hline NC & 11,844 & 2,458 & 1,867 & 756 & 344 & 477 \\
\hline ND & 1,104 & 252 & 47 & 76 & 8 & 24 \\
\hline NE & 2,312 & 518 & 107 & 112 & 237 & 227 \\
\hline $\mathrm{NH}$ & 2,294 & 390 & 102 & 89 & 9 & 34 \\
\hline NJ & 4,007 & 630 & 2,060 & 429 & 562 & 288 \\
\hline NM & 2,625 & 595 & 217 & 173 & 22 & 101 \\
\hline NV & 2,236 & 652 & 40 & 82 & 14 & 51 \\
\hline NY & 12,545 & 1,541 & 291 & 696 & 81 & 307 \\
\hline $\mathrm{OH}$ & 7,971 & 1,102 & 345 & 508 & 100 & 276 \\
\hline OK & 5,235 & 1,368 & 481 & 341 & 87 & 165 \\
\hline OR & 2,098 & 662 & 56 & 119 & 13 & 80 \\
\hline PA & 9,555 & 1,560 & 417 & 401 & 85 & 205 \\
\hline PR & 2,361 & 221 & 16 & 6 & 10 & 6 \\
\hline RI & 2,829 & 500 & 46 & 68 & 23 & 47 \\
\hline SC & 8,518 & 1,724 & 202 & 270 & 38 & 95 \\
\hline SD & 778 & 169 & 139 & 110 & 18 & 39 \\
\hline TN & 5,445 & 1,233 & 161 & 189 & 372 & 252 \\
\hline $\mathrm{TX}$ & 6,334 & 2,007 & 314 & 928 & 73 & 372 \\
\hline UT & 2,619 & 685 & 67 & 174 & 20 & 107 \\
\hline VA & 32,045 & 6,879 & 670 & 1,090 & 74 & 602 \\
\hline VT & 564 & 86 & 120 & 49 & 19 & 30 \\
\hline WA & 8,989 & 2,318 & 121 & 232 & 42 & 157 \\
\hline WI & 3,056 & 868 & 82 & 247 & 2 & 57 \\
\hline WV & 1,502 & 277 & 162 & 74 & 12 & 35 \\
\hline WY & 831 & 185 & 8 & 56 & 6 & 22 \\
\hline Total & 299,095 & 64,716 & 16,034 & 14,669 & 4,367 & 9,258 \\
\hline
\end{tabular}


Table C-1 (continued)

Complete Statistical Match Results and Analysis, Record Level

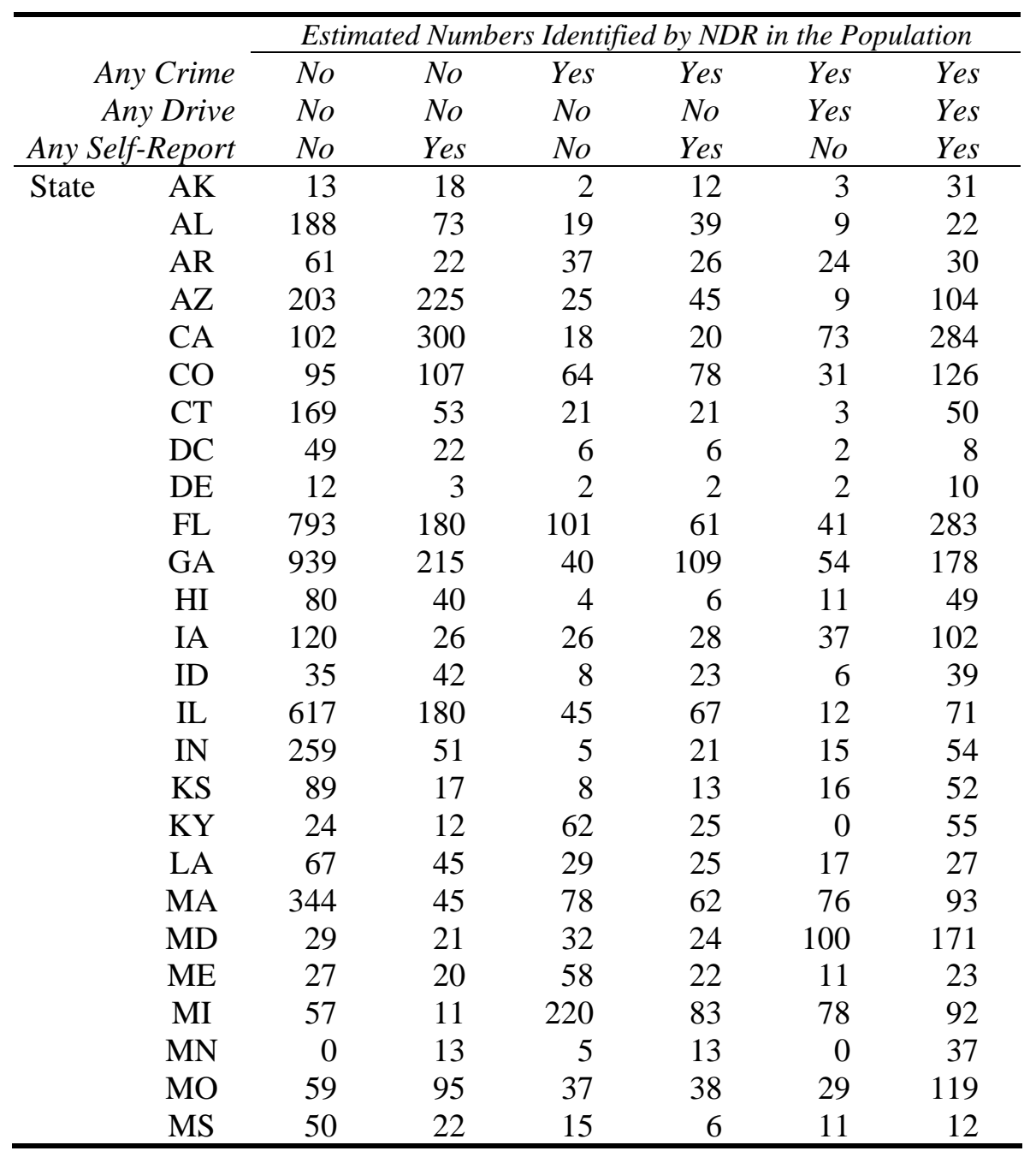


Table C-1 (continued)

Complete Statistical Match Results and Analysis, Record Level

\begin{tabular}{|c|c|c|c|c|c|c|c|}
\hline \multirow{2}{*}{\multicolumn{2}{|c|}{ Any Crime }} & \multicolumn{6}{|c|}{ Estimated Numbers Identified by NDR in the Population } \\
\hline & & No & No & Yes & Yes & Yes & Yes \\
\hline \multicolumn{2}{|c|}{ Any Drive } & No & No & No & No & Yes & Yes \\
\hline \multicolumn{2}{|c|}{ Any Self-Report } & No & Yes & No & Yes & $\mathrm{No}$ & Yes \\
\hline \multirow[t]{27}{*}{ State } & MT & 8 & 8 & 5 & 9 & 1 & 23 \\
\hline & NC & 874 & 246 & 286 & 189 & 185 & 346 \\
\hline & ND & 15 & 7 & 10 & 7 & 1 & 9 \\
\hline & $\mathrm{NE}$ & 31 & 3 & 15 & 7 & 57 & 123 \\
\hline & $\mathrm{NH}$ & 76 & 18 & 31 & 20 & 6 & 26 \\
\hline & NJ & 81 & 29 & 48 & 31 & 348 & 201 \\
\hline & NM & 35 & 8 & 15 & 4 & 3 & 19 \\
\hline & NV & 15 & 30 & 6 & 9 & 6 & 22 \\
\hline & NY & 337 & 62 & 27 & 75 & 11 & 64 \\
\hline & $\mathrm{OH}$ & 319 & 125 & 69 & 105 & 63 & 149 \\
\hline & OK & 176 & 55 & 95 & 68 & 39 & 71 \\
\hline & OR & 210 & 124 & 14 & 52 & 5 & 51 \\
\hline & PA & 192 & 83 & 69 & 71 & 44 & 106 \\
\hline & PR & 0 & 0 & 0 & 0 & 0 & 0 \\
\hline & RI & 132 & 30 & 4 & 13 & 8 & 19 \\
\hline & SC & 227 & 69 & 28 & 66 & 16 & 34 \\
\hline & SD & 41 & 11 & 8 & 13 & 1 & 16 \\
\hline & $\mathrm{TN}$ & 219 & 90 & 15 & 32 & 63 & 95 \\
\hline & TX & 42 & 0 & 3 & 8 & 8 & 65 \\
\hline & UT & 157 & 142 & 12 & 42 & 2 & 44 \\
\hline & VA & 1,721 & 550 & 99 & 194 & 26 & 307 \\
\hline & VT & 11 & 2 & 10 & 7 & 10 & 14 \\
\hline & WA & 300 & 185 & 3 & 33 & 8 & 68 \\
\hline & WI & 143 & 208 & 15 & 48 & 2 & 50 \\
\hline & WV & 40 & 26 & 36 & 18 & 4 & 22 \\
\hline & WY & 22 & 5 & 2 & 5 & 3 & 12 \\
\hline & Total & 9,908 & 3,975 & 1,890 & 1,999 & 1,590 & 4,079 \\
\hline
\end{tabular}


Table C-1 (continued)

Complete Statistical Match Results and Analysis, Record Level

\begin{tabular}{|c|c|c|c|c|c|c|c|}
\hline State & $\begin{array}{l}\text { Total no. } \\
\text { Identified } \\
\text { by NDR in } \\
\text { Population }\end{array}$ & $\begin{array}{c}\text { Total no. } \\
\text { in Pop. } \\
\text { With } \\
\text { LAC } \\
\text { Driving } \\
\text { Offense }\end{array}$ & $\begin{array}{c}\text { No. } \\
\text { Identified } \\
\text { by Both } \\
\text { LACs and } \\
\text { NDR in } \\
\text { Population }\end{array}$ & $\begin{array}{c}\text { No. of } \\
\text { Additional } \\
\text { Offenses } \\
\text { Identified } \\
\text { by adding } \\
\text { NDR } \\
\text { Checks to } \\
\text { LAC } \\
\text { checks }\end{array}$ & $\begin{array}{l}\text { Total no. } \\
\text { of } \\
\text { Offenses } \\
\text { Identified } \\
\text { based on } \\
\text { LACs and } \\
\text { NDR }\end{array}$ & $\begin{array}{c}\text { Pct. of } \\
\text { Known } \\
\text { Driving } \\
\text { Offenses } \\
\text { Identified } \\
\text { by LACs }\end{array}$ & $\begin{array}{c}\text { Pct. of } \\
\text { Driving } \\
\text { Offenses } \\
\text { Identified by } \\
\text { NDR }\end{array}$ \\
\hline AK & 79 & 43 & 34 & 45 & 88 & 48.7 & 89.8 \\
\hline AL & 350 & 346 & 31 & 319 & 665 & 52.1 & 52.6 \\
\hline AR & 199 & 145 & 53 & 146 & 291 & 49.9 & 68.5 \\
\hline $\mathrm{AZ}$ & 611 & 183 & 114 & 498 & 681 & 26.9 & 89.8 \\
\hline CA & 797 & 882 & 357 & 440 & 1,322 & 66.7 & 60.3 \\
\hline $\mathrm{CO}$ & 502 & 271 & 158 & 344 & 615 & 44.1 & 81.6 \\
\hline $\mathrm{CT}$ & 316 & 135 & 53 & 263 & 398 & 33.9 & 79.3 \\
\hline DC & 92 & 55 & 10 & 82 & 137 & 40.1 & 66.9 \\
\hline $\mathrm{DE}$ & 31 & 53 & 12 & 19 & 72 & 73.8 & 42.9 \\
\hline FL & 1,459 & 698 & 324 & 1,135 & 1,833 & 38.1 & 79.6 \\
\hline GA & 1,535 & 621 & 231 & 1,303 & 1,924 & 32.3 & 79.8 \\
\hline HI & 191 & 135 & 60 & 131 & 266 & 50.7 & 71.6 \\
\hline IA & 340 & 363 & 139 & 201 & 564 & 64.3 & 60.3 \\
\hline ID & 153 & 69 & 45 & 108 & 177 & 39.0 & 86.4 \\
\hline IL & 992 & 150 & 83 & 909 & 1,059 & 14.2 & 93.7 \\
\hline IN & 406 & 167 & 69 & 337 & 504 & 33.1 & 80.5 \\
\hline KS & 195 & 146 & 68 & 127 & 273 & 53.4 & 71.4 \\
\hline KY & 177 & 201 & 55 & 123 & 324 & 62.1 & 54.8 \\
\hline LA & 210 & 136 & 44 & 166 & 302 & 45.0 & 69.6 \\
\hline MA & 698 & 353 & 169 & 529 & 882 & 40.0 & 79.1 \\
\hline MD & 378 & 789 & 271 & 106 & 895 & 88.1 & 42.2 \\
\hline $\mathrm{ME}$ & 161 & 62 & 34 & 127 & 189 & 32.8 & 85.0 \\
\hline MI & 541 & 606 & 171 & 370 & 976 & 62.1 & 55.4 \\
\hline $\mathrm{MN}$ & 69 & 127 & 37 & 31 & 158 & 80.2 & 43.3 \\
\hline MO & 377 & 405 & 149 & 228 & 633 & 63.9 & 59.5 \\
\hline MS & 116 & 113 & 24 & 92 & 205 & 55.1 & 56.4 \\
\hline
\end{tabular}


Table C-1 (continued)

Complete Statistical Match Results and Analysis, Record Level

\begin{tabular}{|c|c|c|c|c|c|c|c|}
\hline State & $\begin{array}{l}\text { Total no. } \\
\text { Identified } \\
\text { by NDR in } \\
\text { Population }\end{array}$ & $\begin{array}{c}\text { Total no. } \\
\text { in Pop. } \\
\text { With } \\
\text { LAC } \\
\text { Driving } \\
\text { Offense }\end{array}$ & $\begin{array}{c}\text { No. } \\
\text { Identified } \\
\text { by Both } \\
\text { LACs and } \\
\text { NDR in } \\
\text { Population }\end{array}$ & $\begin{array}{c}\text { No. of } \\
\text { Additional } \\
\text { Offenses } \\
\text { Identified } \\
\text { by adding } \\
\text { NDR } \\
\text { Checks to } \\
\text { LAC } \\
\text { checks }\end{array}$ & $\begin{array}{l}\text { Total no. } \\
\text { of } \\
\text { Offenses } \\
\text { Identified } \\
\text { based on } \\
\text { LACs and } \\
\text { NDR } \\
\end{array}$ & $\begin{array}{c}\text { Pct. of } \\
\text { Known } \\
\text { Driving } \\
\text { Offenses } \\
\text { Identified } \\
\text { by LACs }\end{array}$ & $\begin{array}{c}\text { Pct. of } \\
\text { Driving } \\
\text { Offenses } \\
\text { Identified } \\
\text { by NDR }\end{array}$ \\
\hline MT & 54 & 44 & 24 & 30 & 74 & 59.5 & 73.0 \\
\hline NC & 2,127 & 821 & 531 & 1,595 & 2,416 & 34.0 & 88.0 \\
\hline ND & 48 & 32 & 10 & 38 & 70 & 45.4 & 68.8 \\
\hline NE & 237 & 464 & 181 & 56 & 520 & 89.2 & 45.6 \\
\hline $\mathrm{NH}$ & 178 & 43 & 32 & 146 & 189 & 22.8 & 94.2 \\
\hline NJ & 738 & 850 & 549 & 189 & 1,039 & 81.8 & 71.0 \\
\hline NM & 83 & 123 & 21 & 61 & 184 & 66.7 & 44.9 \\
\hline NV & 88 & 65 & 28 & 60 & 125 & 51.9 & 70.5 \\
\hline NY & 575 & 388 & 75 & 501 & 889 & 43.7 & 64.7 \\
\hline $\mathrm{OH}$ & 829 & 376 & 211 & 617 & 993 & 37.8 & 83.4 \\
\hline OK & 504 & 252 & 110 & 393 & 645 & 39.0 & 78.0 \\
\hline OR & 455 & 93 & 56 & 399 & 492 & 18.9 & 92.5 \\
\hline PA & 566 & 290 & 150 & 416 & 706 & 41.1 & 80.1 \\
\hline PR & 0 & 16 & 0 & 0 & 16 & 100.0 & 0.0 \\
\hline RI & 206 & 70 & 27 & 179 & 249 & 28.1 & 82.7 \\
\hline SC & 440 & 133 & 50 & 390 & 523 & 25.4 & 84.1 \\
\hline SD & 91 & 57 & 17 & 74 & 131 & 43.5 & 69.5 \\
\hline $\mathrm{TN}$ & 514 & 624 & 158 & 356 & 980 & 63.7 & 52.5 \\
\hline $\mathrm{TX}$ & 126 & 445 & 73 & 53 & 498 & 89.3 & 25.4 \\
\hline UT & 399 & 127 & 46 & 353 & 480 & 26.5 & 83.1 \\
\hline VA & 2,897 & 676 & 334 & 2,564 & 3,240 & 20.9 & 89.4 \\
\hline VT & 54 & 49 & 24 & 30 & 79 & 61.8 & 68.5 \\
\hline WA & 598 & 199 & 76 & 522 & 721 & 27.6 & 82.9 \\
\hline WI & 466 & 59 & 52 & 414 & 473 & 12.5 & 98.6 \\
\hline WV & 145 & 47 & 26 & 120 & 167 & 28.2 & 87.2 \\
\hline WY & 49 & 28 & 15 & 34 & 62 & 45.1 & 79.1 \\
\hline Total & 23,441 & 13,625 & 5,669 & 17,772 & 31,397 & 43.4 & 74.7 \\
\hline
\end{tabular}




\section{Appendix D}

Complete Statistical Match Results and Analysis, Subject Level, by State 
D-2 
Table D-1

Complete Statistical Match Results and Analysis, Subject Level

\begin{tabular}{rrrrrrrrrrr}
\hline & \multicolumn{10}{c}{ Sample Frequencies } \\
\cline { 2 - 11 } Any Crime & No & No & No & No & No & No & Yes & Yes & Yes \\
Any Drive & No & No & No & No & No & No & No & No & No \\
Any Self-Report & No & No & No & Yes & Yes & \multicolumn{1}{c}{ Yes } & No & No & No \\
NDR & No & Yes & Total & No & Yes & Total & No & Yes & Total \\
\hline State & AK & 146 & 4 & 150 & 137 & 13 & 150 & 11 & 2 & 13 \\
AL & 147 & 3 & 150 & 144 & 6 & 150 & 101 & 8 & 109 \\
AR & 146 & 4 & 150 & 142 & 8 & 150 & 81 & 29 & 110 \\
AZ & 146 & 4 & 150 & 133 & 17 & 150 & 103 & 24 & 127 \\
CA & 149 & 1 & 150 & 140 & 10 & 150 & 85 & 5 & 90 \\
CO & 148 & 2 & 150 & 140 & 10 & 150 & 86 & 35 & 121 \\
CT & 145 & 5 & 150 & 143 & 7 & 150 & 124 & 17 & 141 \\
DC & 149 & 1 & 150 & 147 & 2 & 149 & 84 & 6 & 90 \\
DE & 148 & 2 & 150 & 147 & 2 & 149 & 129 & 2 & 131 \\
FL & 144 & 6 & 150 & 144 & 6 & 150 & 112 & 14 & 126 \\
GA & 140 & 10 & 150 & 141 & 9 & 150 & 76 & 12 & 88 \\
HI & 148 & 2 & 150 & 146 & 4 & 150 & 92 & 4 & 96 \\
IA & 140 & 10 & 150 & 139 & 11 & 150 & 51 & 13 & 64 \\
ID & 146 & 4 & 150 & 135 & 15 & 150 & 37 & 8 & 45 \\
IL & 141 & 9 & 150 & 138 & 12 & 150 & 102 & 29 & 131 \\
IN & 141 & 9 & 150 & 141 & 9 & 150 & 105 & 5 & 110 \\
KS & 146 & 3 & 149 & 147 & 3 & 150 & 50 & 8 & 58 \\
KY & 149 & 1 & 150 & 148 & 2 & 150 & 126 & 12 & 138 \\
LA & 148 & 2 & 150 & 144 & 6 & 150 & 106 & 21 & 127 \\
MA & 142 & 7 & 149 & 143 & 7 & 150 & 86 & 24 & 110 \\
MD & 149 & 1 & 150 & 147 & 3 & 150 & 47 & 11 & 58 \\
ME & 147 & 3 & 150 & 140 & 10 & 150 & 83 & 53 & 136 \\
MI & 147 & 3 & 150 & 146 & 4 & 150 & 120 & 14 & 134 \\
MN & 150 & 0 & 150 & 147 & 3 & 150 & 141 & 2 & 143 \\
MO & 149 & 1 & 150 & 141 & 9 & 150 & 101 & 12 & 113 \\
MS & 147 & 2 & 149 & 146 & 4 & 150 & 114 & 13 & 127 \\
\hline & & & & & & & & &
\end{tabular}

D-3 
Table D-1 (continued)

Complete Statistical Match Results and Analysis, Subject Level

\begin{tabular}{rrrrrrrrrrr}
\hline & \multicolumn{10}{c}{ Sample Frequencies } \\
\cline { 2 - 11 } Any Crime & No & No & No & No & No & No & Yes & Yes & \multicolumn{1}{c}{ Yes } \\
Any Drive & No & No & No & No & No & No & No & No & No \\
Any Self-Report & No & No & No & Yes & Yes & Yes & No & No & \multicolumn{1}{c}{ No } \\
NDR & No & Yes & Total & \multicolumn{1}{c}{ No } & Yes & Total & No & Yes & Total \\
\hline State & MT & 149 & 1 & 150 & 145 & 5 & 150 & 25 & 5 & 30 \\
NC & 138 & 11 & 149 & 135 & 15 & 150 & 105 & 19 & 124 \\
ND & 148 & 2 & 150 & 146 & 4 & 150 & 37 & 10 & 47 \\
NE & 148 & 2 & 150 & 149 & 1 & 150 & 44 & 7 & 51 \\
NH & 145 & 5 & 150 & 142 & 7 & 149 & 71 & 31 & 102 \\
NJ & 146 & 3 & 149 & 143 & 7 & 150 & 125 & 3 & 128 \\
NM & 148 & 2 & 150 & 148 & 2 & 150 & 124 & 9 & 133 \\
NV & 149 & 1 & 150 & 143 & 7 & 150 & 34 & 6 & 40 \\
NY & 145 & 4 & 149 & 143 & 6 & 149 & 109 & 11 & 120 \\
OH & 144 & 6 & 150 & 133 & 17 & 150 & 92 & 23 & 115 \\
OK & 144 & 5 & 149 & 144 & 6 & 150 & 97 & 24 & 121 \\
OR & 135 & 15 & 150 & 122 & 28 & 150 & 42 & 14 & 56 \\
PA & 146 & 3 & 149 & 142 & 8 & 150 & 101 & 20 & 121 \\
PR & 150 & 0 & 150 & 150 & 0 & 150 & 16 & 0 & 16 \\
RI & 143 & 7 & 150 & 141 & 9 & 150 & 42 & 4 & 46 \\
SC & 146 & 4 & 150 & 144 & 6 & 150 & 110 & 18 & 128 \\
SD & 142 & 8 & 150 & 140 & 10 & 150 & 124 & 8 & 132 \\
TN & 143 & 6 & 149 & 139 & 11 & 150 & 40 & 4 & 44 \\
TX & 149 & 1 & 150 & 150 & 0 & 150 & 122 & 1 & 123 \\
UT & 141 & 9 & 150 & 119 & 31 & 150 & 55 & 12 & 67 \\
VA & 141 & 8 & 149 & 138 & 12 & 150 & 116 & 20 & 136 \\
VT & 147 & 3 & 150 & 84 & 2 & 86 & 110 & 10 & 120 \\
WA & 145 & 5 & 150 & 138 & 12 & 150 & 109 & 3 & 112 \\
WI & 143 & 7 & 150 & 114 & 36 & 150 & 67 & 15 & 82 \\
WV & 146 & 4 & 150 & 136 & 14 & 150 & 109 & 31 & 140 \\
WY & 146 & 4 & 150 & 146 & 4 & 150 & 6 & 2 & 8 \\
\hline Total & 7565 & 225 & 7790 & 7280 & 452 & 7732 & 4385 & 693 & 5078 \\
\hline & & & & & & & & &
\end{tabular}


Table D-1 (continued)

Complete Statistical Match Results and Analysis, Subject Level

\begin{tabular}{rrrrrrrrrrr}
\hline & \multicolumn{10}{c}{ Sample Frequencies } \\
Any Crime & Yes & Yes & Yes & Yes & Yes & Yes & Yes & Yes & Yes \\
Any Drive & No & No & No & Yes & Yes & Yes & Yes & Yes & Yes \\
Any Self-Report & Yes & Yes & \multicolumn{1}{c}{ Yes } & No & No & No & Yes & Yes & Yes \\
NDR & \multicolumn{1}{c}{ No } & Yes & \multicolumn{1}{c|}{ Total } & No & Yes & Total & No & Yes & Total \\
\hline State & AK & 20 & 12 & 32 & 4 & 3 & 7 & 5 & 31 & 36 \\
AL & 71 & 10 & 81 & 37 & 4 & 41 & 63 & 6 & 69 \\
AR & 76 & 15 & 91 & 20 & 20 & 40 & 41 & 18 & 59 \\
AZ & 78 & 13 & 91 & 14 & 9 & 23 & 20 & 38 & 58 \\
CA & 57 & 3 & 60 & 42 & 18 & 60 & 50 & 40 & 90 \\
CO & 63 & 21 & 84 & 13 & 16 & 29 & 27 & 39 & 66 \\
CT & 93 & 8 & 101 & 7 & 2 & 9 & 29 & 20 & 49 \\
DC & 103 & 5 & 108 & 8 & 2 & 10 & 35 & 7 & 42 \\
DE & 45 & 2 & 47 & 16 & 2 & 18 & 25 & 10 & 35 \\
FL & 90 & 6 & 96 & 19 & 5 & 24 & 23 & 30 & 53 \\
GA & 46 & 17 & 63 & 42 & 20 & 62 & 53 & 34 & 87 \\
HI & 57 & 6 & 63 & 28 & 11 & 39 & 43 & 44 & 87 \\
IA & 61 & 12 & 73 & 68 & 18 & 86 & 35 & 42 & 77 \\
ID & 68 & 23 & 91 & 6 & 6 & 12 & 18 & 39 & 57 \\
IL & 92 & 22 & 114 & 11 & 8 & 19 & 15 & 21 & 36 \\
IN & 80 & 10 & 90 & 26 & 14 & 40 & 34 & 26 & 60 \\
KS & 72 & 9 & 81 & 20 & 16 & 36 & 36 & 32 & 68 \\
KY & 96 & 9 & 105 & 12 & 0 & 12 & 26 & 19 & 45 \\
LA & 100 & 10 & 110 & 9 & 14 & 23 & 30 & 10 & 40 \\
MA & 49 & 18 & 67 & 19 & 21 & 40 & 46 & 37 & 83 \\
MD & 57 & 4 & 61 & 57 & 35 & 92 & 60 & 29 & 89 \\
ME & 43 & 22 & 65 & 4 & 10 & 14 & 24 & 23 & 47 \\
MI & 98 & 9 & 107 & 10 & 6 & 16 & 33 & 10 & 43 \\
MN & 97 & 5 & 102 & 7 & 0 & 7 & 30 & 17 & 47 \\
MO & 66 & 7 & 73 & 26 & 11 & 37 & 47 & 30 & 77 \\
MS & 77 & 4 & 81 & 14 & 9 & 23 & 59 & 10 & 69 \\
\hline & & & & & & & & &
\end{tabular}


Table D-1 (continued)

Complete Statistical Match Results and Analysis, Subject Level

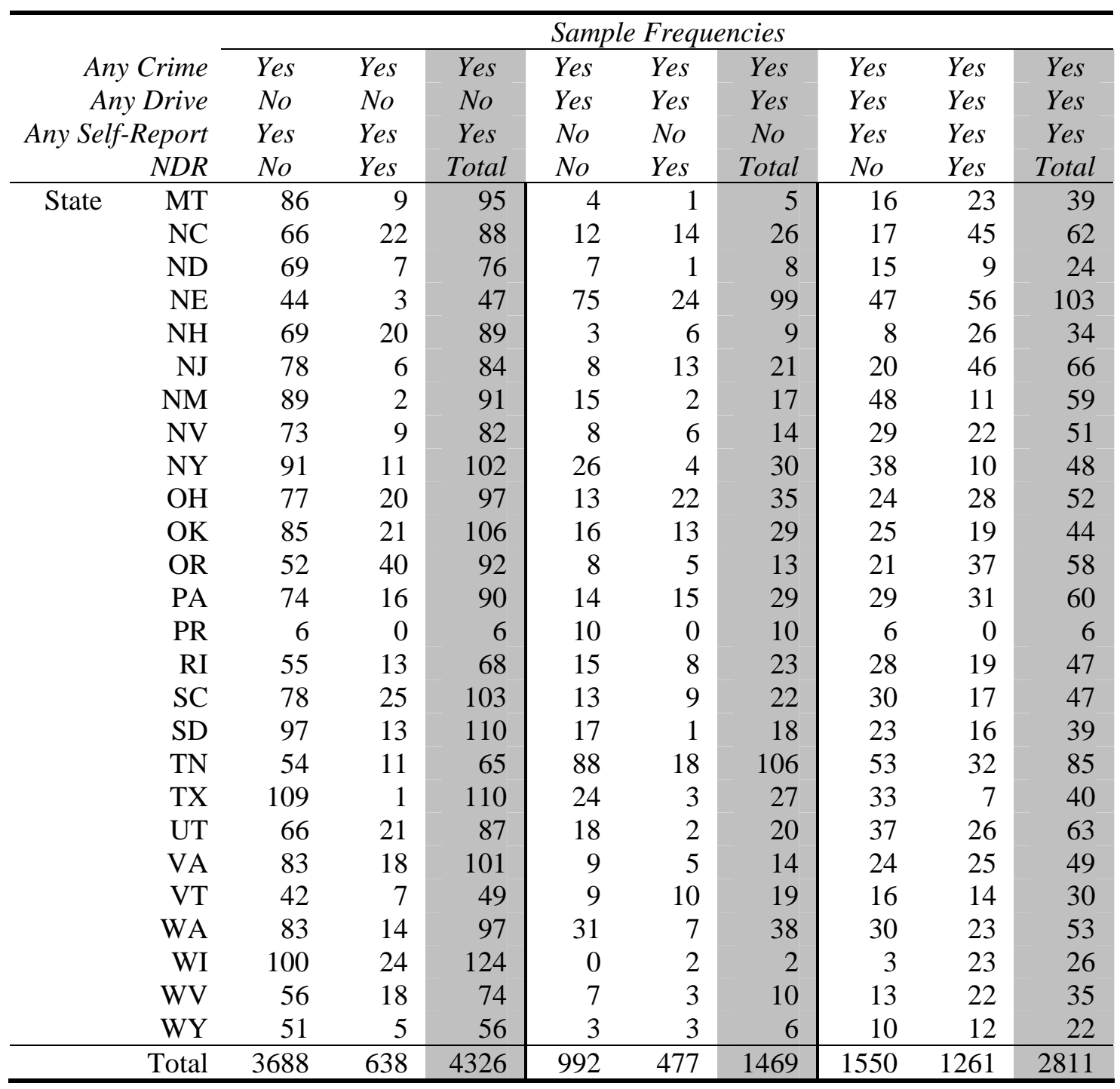

D-6 
Table D-1 (continued)

Complete Statistical Match Results and Analysis, Subject Level

\begin{tabular}{rrrrrrr}
\hline & \multicolumn{7}{c}{ Percent Identified by NDR in Sample } \\
\cline { 2 - 7 } Any Crime & No & No & Yes & Yes & Yes & Yes \\
Any Drive & No & No & No & No & Yes & Yes \\
\multicolumn{1}{l}{ Any Self-Report } & No & Yes & \multicolumn{1}{c}{ No } & Yes & \multicolumn{1}{c}{ No } & Yes \\
\hline \multicolumn{1}{l}{ State AK } & 2.7 & 8.7 & 15.4 & 37.5 & 42.9 & 86.1 \\
AL & 2.0 & 4.0 & 7.3 & 12.3 & 9.8 & 8.7 \\
AR & 2.7 & 5.3 & 26.4 & 16.5 & 50.0 & 30.5 \\
AZ & 2.7 & 11.3 & 18.9 & 14.3 & 39.1 & 65.5 \\
CA & 0.7 & 6.7 & 5.6 & 5.0 & 30.0 & 44.4 \\
CO & 1.3 & 6.7 & 28.9 & 25.0 & 55.2 & 59.1 \\
CT & 3.3 & 4.7 & 12.1 & 7.9 & 22.2 & 40.8 \\
DC & 0.7 & 1.3 & 6.7 & 4.6 & 20.0 & 16.7 \\
DE & 1.3 & 1.3 & 1.5 & 4.3 & 11.1 & 28.6 \\
FL & 4.0 & 4.0 & 11.1 & 6.3 & 20.8 & 56.6 \\
GA & 6.7 & 6.0 & 13.6 & 27.0 & 32.3 & 39.1 \\
HI & 1.3 & 2.7 & 4.2 & 9.5 & 28.2 & 50.6 \\
IA & 6.7 & 7.3 & 20.3 & 16.4 & 20.9 & 54.5 \\
ID & 2.7 & 10.0 & 17.8 & 25.3 & 50.0 & 68.4 \\
IL & 6.0 & 8.0 & 22.1 & 19.3 & 42.1 & 58.3 \\
IN & 6.0 & 6.0 & 4.5 & 11.1 & 35.0 & 43.3 \\
KS & 2.0 & 2.0 & 13.8 & 11.1 & 44.4 & 47.1 \\
KY & 0.7 & 1.3 & 8.7 & 8.6 & 0.0 & 42.2 \\
LA & 1.3 & 4.0 & 16.5 & 9.1 & 60.9 & 25.0 \\
MA & 4.7 & 4.7 & 21.8 & 26.9 & 52.5 & 44.6 \\
MD & 0.7 & 2.0 & 19.0 & 6.6 & 38.0 & 32.6 \\
ME & 2.0 & 6.7 & 39.0 & 33.8 & 71.4 & 48.9 \\
MI & 2.0 & 2.7 & 10.4 & 8.4 & 37.5 & 23.3 \\
MN & 0.0 & 2.0 & 1.4 & 4.9 & 0.0 & 36.2 \\
MO & 0.7 & 6.0 & 10.6 & 9.6 & 29.7 & 39.0 \\
MS & 1.3 & 2.7 & 10.2 & 4.9 & 39.1 & 14.5 \\
\hline & & & & & &
\end{tabular}


Table D-1 (continued)

Complete Statistical Match Results and Analysis, Subject Level

\begin{tabular}{|c|c|c|c|c|c|c|c|}
\hline \multirow{2}{*}{\multicolumn{2}{|c|}{ Any Crime }} & \multicolumn{6}{|c|}{ Percent Identified by NDR in Sample } \\
\hline & & No & $\mathrm{No}$ & Yes & Yes & Yes & Yes \\
\hline & Drive & No & No & No & No & Yes & Yes \\
\hline \multicolumn{2}{|c|}{ Any Self-Report } & No & Yes & No & Yes & No & Yes \\
\hline \multirow[t]{27}{*}{ State } & $\mathrm{MT}$ & 0.7 & 3.3 & 16.7 & 9.5 & 20.0 & 59.0 \\
\hline & NC & 7.4 & 10.0 & 15.3 & 25.0 & 53.8 & 72.6 \\
\hline & ND & 1.3 & 2.7 & 21.3 & 9.2 & 12.5 & 37.5 \\
\hline & NE & 1.3 & 0.7 & 13.7 & 6.4 & 24.2 & 54.4 \\
\hline & $\mathrm{NH}$ & 3.3 & 4.7 & 30.4 & 22.5 & 66.7 & 76.5 \\
\hline & NJ & 2.0 & 4.7 & 2.3 & 7.1 & 61.9 & 69.7 \\
\hline & NM & 1.3 & 1.3 & 6.8 & 2.2 & 11.8 & 18.6 \\
\hline & NV & 0.7 & 4.7 & 15.0 & 11.0 & 42.9 & 43.1 \\
\hline & NY & 2.7 & 4.0 & 9.2 & 10.8 & 13.3 & 20.8 \\
\hline & $\mathrm{OH}$ & 4.0 & 11.3 & 20.0 & 20.6 & 62.9 & 53.8 \\
\hline & OK & 3.4 & 4.0 & 19.8 & 19.8 & 44.8 & 43.2 \\
\hline & OR & 10.0 & 18.7 & 25.0 & 43.5 & 38.5 & 63.8 \\
\hline & PA & 2.0 & 5.3 & 16.5 & 17.8 & 51.7 & 51.7 \\
\hline & PR & 0.0 & 0.0 & 0.0 & 0.0 & 0.0 & 0.0 \\
\hline & RI & 4.7 & 6.0 & 8.7 & 19.1 & 34.8 & 40.4 \\
\hline & SC & 2.7 & 4.0 & 14.1 & 24.3 & 40.9 & 36.2 \\
\hline & SD & 5.3 & 6.7 & 6.1 & 11.8 & 5.6 & 41.0 \\
\hline & $\mathrm{TN}$ & 4.0 & 7.3 & 9.1 & 16.9 & 17.0 & 37.6 \\
\hline & TX & 0.7 & 0.0 & 0.8 & 0.9 & 11.1 & 17.5 \\
\hline & UT & 6.0 & 20.7 & 17.9 & 24.1 & 10.0 & 41.3 \\
\hline & VA & 5.4 & 8.0 & 14.7 & 17.8 & 35.7 & 51.0 \\
\hline & VT & 2.0 & 2.3 & 8.3 & 14.3 & 52.6 & 46.7 \\
\hline & WA & 3.3 & 8.0 & 2.7 & 14.4 & 18.4 & 43.4 \\
\hline & WI & 4.7 & 24.0 & 18.3 & 19.4 & 100.0 & 88.5 \\
\hline & WV & 2.7 & 9.3 & 22.1 & 24.3 & 30.0 & 62.9 \\
\hline & WY & 2.7 & 2.7 & 25.0 & 8.9 & 50.0 & 54.5 \\
\hline & Total & 2.9 & 5.8 & 13.6 & 14.7 & 32.5 & 44.9 \\
\hline
\end{tabular}


Table D-1 (continued)

Complete Statistical Match Results and Analysis, Subject Level

\begin{tabular}{cccc}
\hline Total in & $\begin{array}{c}\text { Total in } \\
\text { Population } \\
\text { with } \\
\text { (includes } \\
\text { missing } \\
\text { values) }\end{array}$ & $\begin{array}{c}\text { Total in Pop. } \\
\text { NonMissing } \\
\text { Values }^{a}\end{array}$ & $\begin{array}{c}\text { With LAC } \\
\text { Driving } \\
\text { Offense }\end{array}$ \\
\hline AK & 800 & 797 & 43 \\
AL & 12,140 & 12,118 & 346 \\
AR & 3,138 & 3,134 & 145 \\
AZ & 10,257 & 10,228 & 182 \\
CA & 21,541 & 21,463 & 882 \\
CO & 9,576 & 9,530 & 270 \\
CT & 6,763 & 6,758 & 135 \\
DC & 9,269 & 9,238 & 55 \\
DE & 1,336 & 1,336 & 53 \\
FL & 26,943 & 26,879 & 696 \\
GA & 19,021 & 18,976 & 620 \\
HI & 7,844 & 7,832 & 135 \\
IA & 2,833 & 2,829 & 363 \\
ID & 1,939 & 1,932 & 68 \\
IL & 13,244 & 13,229 & 150 \\
IN & 5,656 & 5,650 & 167 \\
KS & 5,601 & 5,588 & 144 \\
KY & 5,743 & 5,734 & 201 \\
LA & 6,749 & 6,740 & 136 \\
MA & 9,238 & 9,227 & 353 \\
MD & 6,850 & 6,758 & 787 \\
ME & 1,921 & 1,915 & 62 \\
MI & 6,969 & 6,944 & 606 \\
MN & 4,708 & 4,694 & 127 \\
MO & 11,592 & 11,580 & 405 \\
MS & 4,910 & 4,906 & 112 \\
\hline
\end{tabular}

${ }^{a}$ Nonmissing values refers to cases not missing values on variables indicating any criminal activity, any driving offense, and any self-report. 
Table D-1 (continued)

Complete Statistical Match Results and Analysis, Subject Level

\begin{tabular}{|c|c|c|c|}
\hline State & $\begin{array}{l}\text { Total in } \\
\text { Population } \\
\text { (includes } \\
\text { missing } \\
\text { values) }\end{array}$ & $\begin{array}{c}\text { Total in } \\
\text { Population } \\
\text { with } \\
\text { NonMissing }^{\text {Values }}{ }^{a}\end{array}$ & $\begin{array}{c}\text { Total in Pop. } \\
\text { With LAC } \\
\text { Driving } \\
\text { Offense }\end{array}$ \\
\hline MT & 1,652 & 1,649 & 44 \\
\hline NC & 17,842 & 17,730 & 819 \\
\hline ND & 1,511 & 1,511 & 32 \\
\hline $\mathrm{NE}$ & 3,518 & 3,512 & 464 \\
\hline $\mathrm{NH}$ & 2,918 & 2,915 & 43 \\
\hline NJ & 7,985 & 7,969 & 850 \\
\hline NM & 3,738 & 3,729 & 123 \\
\hline $\mathrm{NV}$ & 3,076 & 3,073 & 65 \\
\hline NY & 15,478 & 15,439 & 388 \\
\hline $\mathrm{OH}$ & 10,305 & 10,289 & 376 \\
\hline OK & 7,679 & 7,673 & 252 \\
\hline OR & 3,020 & 3,019 & 93 \\
\hline $\mathrm{PA}$ & 12,236 & 12,211 & 289 \\
\hline PR & 2,617 & 2,615 & 16 \\
\hline RI & 3,518 & 3,511 & 70 \\
\hline SC & 10,852 & 10,839 & 133 \\
\hline SD & 1,254 & 1,253 & 57 \\
\hline $\mathrm{TN}$ & 7,649 & 7,635 & 624 \\
\hline $\mathrm{TX}$ & 10,054 & 10,023 & 443 \\
\hline UT & 3,672 & 3,671 & 127 \\
\hline VA & 41,533 & 41,315 & 676 \\
\hline VT & 869 & 868 & 49 \\
\hline WA & 11,868 & 11,851 & 197 \\
\hline WI & 4,310 & 4,303 & 59 \\
\hline WV & 2,062 & 2,056 & 47 \\
\hline WY & 1,110 & 1,108 & 28 \\
\hline Total & 408,907 & 407,782 & 13,607 \\
\hline
\end{tabular}

${ }^{a}$ Nonmissing values refers to cases not missing values on variables indicating any criminal activity, any driving offense, and any self-report. 
Table D-1 (continued)

Complete Statistical Match Results and Analysis, Subject Level

\begin{tabular}{|c|c|c|c|c|c|c|c|}
\hline \multirow{2}{*}{\multicolumn{2}{|c|}{ Any Crime }} & \multicolumn{6}{|c|}{ Total Population } \\
\hline & & No & No & Yes & Yes & Yes & Yes \\
\hline \multicolumn{2}{|c|}{ Any Drive } & No & No & No & No & Yes & Yes \\
\hline \multicolumn{2}{|c|}{ Any Self-Report } & No & Yes & $\mathrm{No}$ & Yes & No & Yes \\
\hline \multirow[t]{26}{*}{ State } & AK & 503 & 206 & 13 & 32 & 7 & 36 \\
\hline & AL & 9,372 & 1,828 & 254 & 316 & 92 & 254 \\
\hline & AR & 2,272 & 421 & 139 & 157 & 47 & 98 \\
\hline & $\mathrm{AZ}$ & 7,619 & 1,978 & 132 & 314 & 24 & 158 \\
\hline & CA & 15,359 & 4,497 & 328 & 397 & 243 & 639 \\
\hline & $\mathrm{CO}$ & 7,121 & 1,607 & 220 & 311 & 57 & 213 \\
\hline & CT & 5,063 & 1,123 & 174 & 259 & 13 & 122 \\
\hline & DC & 7,353 & 1,621 & 90 & 119 & 10 & 45 \\
\hline & $\mathrm{DE}$ & 912 & 192 & 131 & 46 & 18 & 35 \\
\hline & FL & 19,797 & 4,506 & 906 & 966 & 198 & 498 \\
\hline & GA & 14,071 & 3,585 & 295 & 402 & 166 & 454 \\
\hline & HI & 6,026 & 1,506 & 96 & 67 & 39 & 96 \\
\hline & IA & 1,807 & 358 & 129 & 172 & 176 & 187 \\
\hline & ID & 1,309 & 418 & 45 & 91 & 12 & 56 \\
\hline & IL & 10,285 & 2,244 & 202 & 346 & 29 & 121 \\
\hline & IN & 4,320 & 856 & 118 & 189 & 42 & 125 \\
\hline & KS & 4,408 & 857 & 58 & 120 & 36 & 108 \\
\hline & KY & 3,665 & 869 & 712 & 287 & 71 & 130 \\
\hline & LA & 5,022 & 1,130 & 174 & 277 & 28 & 108 \\
\hline & MA & 7,315 & 971 & 357 & 230 & 144 & 209 \\
\hline & MD & 4,388 & 1,052 & 169 & 360 & 263 & 524 \\
\hline & $\mathrm{ME}$ & 1,340 & 299 & 149 & 65 & 15 & 47 \\
\hline & MI & 2,863 & 394 & 2,099 & 979 & 209 & 397 \\
\hline & MN & 3,277 & 643 & 381 & 264 & 24 & 103 \\
\hline & MO & 8,853 & 1,583 & 344 & 393 & 99 & 306 \\
\hline & MS & 3,713 & 824 & 143 & 112 & 29 & 83 \\
\hline
\end{tabular}


Table D-1 (continued)

Complete Statistical Match Results and Analysis, Subject Level

\begin{tabular}{|c|c|c|c|c|c|c|c|}
\hline \multirow{4}{*}{\multicolumn{2}{|c|}{$\begin{array}{l}\text { Any Crime } \\
\text { Any Drive } \\
\text { Any Self-Report }\end{array}$}} & \multicolumn{6}{|c|}{ Total Population } \\
\hline & & $\mathrm{No}$ & $\mathrm{No}$ & Yes & Yes & Yes & Yes \\
\hline & & No & No & No & No & Yes & Yes \\
\hline & & No & Yes & No & Yes & No & Yes \\
\hline \multirow[t]{27}{*}{ State } & MT & 1,251 & 229 & 30 & 95 & 5 & 39 \\
\hline & NC & 11,836 & 2,447 & 1,865 & 755 & 342 & 477 \\
\hline & ND & 1,104 & 252 & 47 & 76 & 8 & 24 \\
\hline & NE & 2,311 & 518 & 107 & 112 & 237 & 227 \\
\hline & $\mathrm{NH}$ & 2,292 & 388 & 102 & 89 & 9 & 34 \\
\hline & NJ & 4,003 & 629 & 2,058 & 426 & 562 & 288 \\
\hline & NM & 2,621 & 595 & 217 & 173 & 22 & 101 \\
\hline & NV & 2,235 & 651 & 40 & 81 & 14 & 51 \\
\hline & NY & 12,527 & 1,534 & 291 & 695 & 81 & 307 \\
\hline & $\mathrm{OH}$ & 7,962 & 1,096 & 345 & 506 & 100 & 276 \\
\hline & OK & 5,231 & 1,368 & 481 & 341 & 87 & 165 \\
\hline & OR & 2,091 & 660 & 56 & 117 & 13 & 80 \\
\hline & PA & 9,547 & 1,558 & 417 & 396 & 85 & 204 \\
\hline & PR & 2,356 & 221 & 16 & 6 & 10 & 6 \\
\hline & RI & 2,827 & 500 & 46 & 68 & 23 & 47 \\
\hline & SC & 8,512 & 1,721 & 202 & 269 & 38 & 95 \\
\hline & SD & 778 & 169 & 139 & 110 & 18 & 39 \\
\hline & $\mathrm{TN}$ & 5,432 & 1,227 & 161 & 187 & 372 & 252 \\
\hline & $\mathrm{TX}$ & 6,332 & 2,006 & 314 & 925 & 73 & 370 \\
\hline & UT & 2,618 & 685 & 67 & 174 & 20 & 107 \\
\hline & VA & 32,012 & 6,862 & 668 & 1,085 & 74 & 602 \\
\hline & VT & 564 & 86 & 120 & 49 & 19 & 30 \\
\hline & WA & 8,983 & 2,316 & 121 & 232 & 42 & 155 \\
\hline & WI & 3,048 & 866 & 82 & 247 & 2 & 57 \\
\hline & WV & 1,496 & 277 & 162 & 74 & 12 & 35 \\
\hline & WY & 831 & 185 & 8 & 56 & 6 & 22 \\
\hline & Total & 298,833 & 64,614 & 16,020 & 14,615 & 4,365 & 9,242 \\
\hline
\end{tabular}


Table D-1 (continued)

Complete Statistical Match Results and Analysis, Subject Level

\begin{tabular}{crrrrrr}
\hline & \multicolumn{6}{c}{ Estimated Numbers Identified by NDR in the Population } \\
\cline { 2 - 6 } Any Crime & No & No & Yes & Yes & Yes & Yes \\
Any Drive & No & No & No & No & Yes & Yes \\
Any Self-Report & No & Yes & No & Yes & No & Yes \\
\hline State & 13 & 18 & 2 & 12 & 3 & 31 \\
AL & 187 & 73 & 19 & 39 & 9 & 22 \\
AR & 61 & 22 & 37 & 26 & 24 & 30 \\
AZ & 203 & 224 & 25 & 45 & 9 & 104 \\
CA & 102 & 300 & 18 & 20 & 73 & 284 \\
CO & 95 & 107 & 64 & 78 & 31 & 126 \\
CT & 169 & 52 & 21 & 21 & 3 & 50 \\
DC & 49 & 22 & 6 & 6 & 2 & 8 \\
DE & 12 & 3 & 2 & 2 & 2 & 10 \\
FL & 792 & 180 & 101 & 60 & 41 & 282 \\
GA & 938 & 215 & 40 & 108 & 54 & 177 \\
HI & 80 & 40 & 4 & 6 & 11 & 49 \\
IA & 120 & 26 & 26 & 28 & 37 & 102 \\
ID & 35 & 42 & 8 & 23 & 6 & 38 \\
IL & 617 & 180 & 45 & 67 & 12 & 71 \\
IN & 259 & 51 & 5 & 21 & 15 & 54 \\
KS & 89 & 17 & 8 & 13 & 16 & 51 \\
KY & 24 & 12 & 62 & 25 & 0 & 55 \\
LA & 67 & 45 & 29 & 25 & 17 & 27 \\
MA & 344 & 45 & 78 & 62 & 76 & 93 \\
MD & 29 & 21 & 32 & 24 & 100 & 171 \\
ME & 27 & 20 & 58 & 22 & 11 & 23 \\
MI & 57 & 11 & 219 & 82 & 78 & 92 \\
MN & 0 & 13 & 5 & 13 & 0 & 37 \\
MO & 59 & 95 & 37 & 38 & 29 & 119 \\
MS & 50 & 22 & 15 & 6 & 11 & 12 \\
\hline & & & & & &
\end{tabular}


Table D-1 (continued)

Complete Statistical Match Results and Analysis, Subject Level

\begin{tabular}{|c|c|c|c|c|c|c|c|}
\hline \multirow{2}{*}{\multicolumn{2}{|c|}{ Any Crime }} & \multicolumn{6}{|c|}{ Estimated Numbers Identified by NDR in the Population } \\
\hline & & No & No & Yes & Yes & Yes & Yes \\
\hline \multicolumn{2}{|c|}{ Any Drive } & No & No & No & No & Yes & Yes \\
\hline \multicolumn{2}{|c|}{ Any Self-Report } & No & Yes & No & Yes & No & Yes \\
\hline \multirow[t]{27}{*}{ State } & MT & 8 & 8 & 5 & 9 & 1 & 23 \\
\hline & NC & 874 & 245 & 286 & 189 & 184 & 346 \\
\hline & ND & 15 & 7 & 10 & 7 & 1 & 9 \\
\hline & NE & 31 & 3 & 15 & 7 & 57 & 123 \\
\hline & $\mathrm{NH}$ & 76 & 18 & 31 & 20 & 6 & 26 \\
\hline & NJ & 81 & 29 & 48 & 30 & 348 & 201 \\
\hline & NM & 35 & 8 & 15 & 4 & 3 & 19 \\
\hline & NV & 15 & 30 & 6 & 9 & 6 & 22 \\
\hline & NY & 336 & 62 & 27 & 75 & 11 & 64 \\
\hline & $\mathrm{OH}$ & 318 & 124 & 69 & 104 & 63 & 149 \\
\hline & OK & 176 & 55 & 95 & 68 & 39 & 71 \\
\hline & OR & 209 & 123 & 14 & 51 & 5 & 51 \\
\hline & $\mathrm{PA}$ & 192 & 83 & 69 & 70 & 44 & 105 \\
\hline & PR & 0 & 0 & 0 & 0 & 0 & 0 \\
\hline & RI & 132 & 30 & 4 & 13 & 8 & 19 \\
\hline & SC & 227 & 69 & 28 & 65 & 16 & 34 \\
\hline & SD & 41 & 11 & 8 & 13 & 1 & 16 \\
\hline & TN & 219 & 90 & 15 & 32 & 63 & 95 \\
\hline & TX & 42 & 0 & 3 & 8 & 8 & 65 \\
\hline & UT & 157 & 142 & 12 & 42 & 2 & 44 \\
\hline & VA & 1,719 & 549 & 98 & 193 & 26 & 307 \\
\hline & VT & 11 & 2 & 10 & 7 & 10 & 14 \\
\hline & WA & 299 & 185 & 3 & 33 & 8 & 67 \\
\hline & WI & 142 & 208 & 15 & 48 & 2 & 50 \\
\hline & WV & 40 & 26 & 36 & 18 & 4 & 22 \\
\hline & WY & 22 & 5 & 2 & 5 & 3 & 12 \\
\hline & Total & 9,898 & 3,968 & 1,888 & 1,992 & 1,589 & 4,072 \\
\hline
\end{tabular}


Table D-1 (continued)

Complete Statistical Match Results and Analysis, Subject Level

\begin{tabular}{|c|c|c|c|c|c|c|c|}
\hline State & $\begin{array}{l}\text { Total no. } \\
\text { Identified } \\
\text { by NDR in } \\
\text { Population }\end{array}$ & $\begin{array}{c}\text { Total no. } \\
\text { in Pop. } \\
\text { With } \\
\text { LAC } \\
\text { Driving } \\
\text { Offense }\end{array}$ & $\begin{array}{l}\text { No. } \\
\text { Identified } \\
\text { by Both } \\
\text { LACs and } \\
\text { NDR in } \\
\text { Population }\end{array}$ & $\begin{array}{c}\text { No. of } \\
\text { Additional } \\
\text { Offenses } \\
\text { Identified } \\
\text { by adding } \\
\text { NDR } \\
\text { Checks to } \\
\text { LAC } \\
\text { checks }\end{array}$ & $\begin{array}{l}\text { Total no. } \\
\text { of } \\
\text { Offenses } \\
\text { Identified } \\
\text { based on } \\
\text { LACs and } \\
\text { NDR }\end{array}$ & $\begin{array}{c}\text { Pct. of } \\
\text { Known } \\
\text { Driving } \\
\text { Offenses } \\
\text { Identified } \\
\text { by LACs }\end{array}$ & $\begin{array}{c}\text { Pct. of } \\
\text { Driving } \\
\text { Offenses } \\
\text { Identified } \\
\text { by NDR }\end{array}$ \\
\hline AK & 79 & 43 & 34 & 45 & 88 & 48.7 & 89.8 \\
\hline $\mathrm{AL}$ & 349 & 346 & 31 & 318 & 664 & 52.1 & 52.6 \\
\hline AR & 199 & 145 & 53 & 146 & 291 & 49.9 & 68.5 \\
\hline $\mathrm{AZ}$ & 610 & 183 & 113 & 497 & 680 & 26.9 & 89.7 \\
\hline CA & 797 & 882 & 357 & 440 & 1,322 & 66.7 & 60.3 \\
\hline $\mathrm{CO}$ & 501 & 271 & 157 & 343 & 614 & 44.1 & 81.5 \\
\hline CT & 315 & 135 & 53 & 263 & 398 & 33.9 & 79.3 \\
\hline DC & 92 & 55 & 10 & 82 & 137 & 40.1 & 66.9 \\
\hline $\mathrm{DE}$ & 31 & 53 & 12 & 19 & 72 & 73.9 & 42.8 \\
\hline FL & 1,456 & 698 & 323 & 1,133 & 1,831 & 38.1 & 79.5 \\
\hline GA & 1,533 & 621 & 231 & 1,302 & 1,923 & 32.3 & 79.7 \\
\hline $\mathrm{HI}$ & 190 & 135 & 60 & 131 & 266 & 50.8 & 71.6 \\
\hline IA & 340 & 363 & 139 & 201 & 564 & 64.3 & 60.3 \\
\hline ID & 152 & 69 & 44 & 108 & 177 & 39.0 & 86.0 \\
\hline IL & 991 & 150 & 83 & 908 & 1,058 & 14.2 & 93.6 \\
\hline IN & 406 & 167 & 69 & 337 & 504 & 33.1 & 80.5 \\
\hline KS & 194 & 146 & 67 & 127 & 273 & 53.4 & 71.0 \\
\hline $\mathrm{KY}$ & 177 & 201 & 55 & 123 & 324 & 62.1 & 54.8 \\
\hline LA & 210 & 136 & 44 & 166 & 302 & 45.0 & 69.6 \\
\hline MA & 697 & 353 & 169 & 529 & 882 & 40.0 & 79.1 \\
\hline MD & 377 & 789 & 271 & 106 & 895 & 88.2 & 42.1 \\
\hline $\mathrm{ME}$ & 161 & 62 & 34 & 127 & 189 & 32.8 & 85.0 \\
\hline MI & 540 & 606 & 171 & 369 & 975 & 62.1 & 55.4 \\
\hline $\mathrm{MN}$ & 68 & 127 & 37 & 31 & 158 & 80.3 & 43.2 \\
\hline MO & 377 & 405 & 149 & 228 & 633 & 64.0 & 59.5 \\
\hline MS & 115 & 113 & 23 & 92 & 205 & 55.1 & 56.3 \\
\hline
\end{tabular}


Table D-1 (continued)

Complete Statistical Match Results and Analysis, Subject Level

\begin{tabular}{|c|c|c|c|c|c|c|c|}
\hline State & $\begin{array}{l}\text { Total no. } \\
\text { Identified } \\
\text { by NDR in } \\
\text { Population }\end{array}$ & $\begin{array}{c}\text { Total no. } \\
\text { in Pop. } \\
\text { With } \\
\text { LAC } \\
\text { Driving } \\
\text { Offense }\end{array}$ & $\begin{array}{c}\text { No. } \\
\text { Identified } \\
\text { by Both } \\
\text { LACs and } \\
\text { NDR in } \\
\text { Population }\end{array}$ & $\begin{array}{c}\text { No. of } \\
\text { Additional } \\
\text { Offenses } \\
\text { Identified } \\
\text { by adding } \\
\text { NDR } \\
\text { Checks to } \\
\text { LAC } \\
\text { checks }\end{array}$ & $\begin{array}{l}\text { Total no. } \\
\text { of } \\
\text { Offenses } \\
\text { Identified } \\
\text { based on } \\
\text { LACs and } \\
\text { NDR }\end{array}$ & $\begin{array}{c}\text { Pct. of } \\
\text { Known } \\
\text { Driving } \\
\text { Offenses } \\
\text { Identified } \\
\text { by LACs }\end{array}$ & $\begin{array}{c}\text { Pct. of } \\
\text { Driving } \\
\text { Offenses } \\
\text { Identified } \\
\text { by NDR }\end{array}$ \\
\hline MT & 54 & 44 & 24 & 30 & 74 & 59.5 & 73.0 \\
\hline NC & 2,123 & 821 & 530 & 1593 & 2,414 & 34.0 & 88.0 \\
\hline ND & 48 & 32 & 10 & 38 & 70 & 45.4 & 68.8 \\
\hline $\mathrm{NE}$ & 237 & 464 & 181 & 56 & 520 & 89.2 & 45.6 \\
\hline $\mathrm{NH}$ & 178 & 43 & 32 & 146 & 189 & 22.8 & 94.2 \\
\hline NJ & 737 & 850 & 549 & 189 & 1,039 & 81.8 & 71.0 \\
\hline NM & 83 & 123 & 21 & 61 & 184 & 66.7 & 44.9 \\
\hline NV & 88 & 65 & 28 & 60 & 125 & 51.9 & 70.4 \\
\hline NY & 574 & 388 & 75 & 500 & 888 & 43.7 & 64.7 \\
\hline $\mathrm{OH}$ & 827 & 376 & 211 & 616 & 992 & 37.9 & 83.4 \\
\hline OK & 503 & 252 & 110 & 393 & 645 & 39.1 & 78.0 \\
\hline OR & 453 & 93 & 56 & 397 & 490 & 19.0 & 92.5 \\
\hline $\mathrm{PA}$ & 564 & 290 & 149 & 415 & 705 & 41.2 & 80.0 \\
\hline PR & 0 & 16 & 0 & 0 & 16 & 100.0 & 0.0 \\
\hline RI & 206 & 70 & 27 & 179 & 249 & 28.1 & 82.7 \\
\hline SC & 439 & 133 & 50 & 390 & 523 & 25.5 & 84.1 \\
\hline SD & 91 & 57 & 17 & 74 & 131 & 43.5 & 69.5 \\
\hline $\mathrm{TN}$ & 513 & 624 & 158 & 355 & 979 & 63.7 & 52.4 \\
\hline $\mathrm{TX}$ & 126 & 445 & 73 & 53 & 498 & 89.3 & 25.3 \\
\hline UT & 399 & 127 & 46 & 353 & 480 & 26.5 & 83.1 \\
\hline VA & 2,893 & 676 & 334 & 2,559 & 3,235 & 20.9 & 89.4 \\
\hline VT & 54 & 49 & 24 & 30 & 79 & 61.8 & 68.5 \\
\hline WA & 596 & 199 & 75 & 521 & 720 & 27.6 & 82.8 \\
\hline WI & 465 & 59 & 52 & 413 & 472 & 12.5 & 98.6 \\
\hline WV & 145 & 47 & 26 & 120 & 167 & 28.2 & 87.2 \\
\hline WY & 49 & 28 & 15 & 34 & 62 & 45.1 & 79.1 \\
\hline Total & 2,3408 & 13,625 & 5,661 & 17,747 & 31,372 & 43.4 & 74.6 \\
\hline
\end{tabular}




\section{Appendix E}

Complete Statistical Match Results and Analysis, Aggregated by Subject, Across All States 
E-2 
Table E-1

Sample Totals, Aggregated by Subject

\begin{tabular}{|c|c|c|c|c|c|c|}
\hline \multirow{2}{*}{$\begin{array}{c}\text { Any } \\
\text { Criminal } \\
\text { Offense }\end{array}$} & \multirow{2}{*}{$\begin{array}{c}\text { Any } \\
\text { Driving } \\
\text { Offense }\end{array}$} & \multirow{2}{*}{$\begin{array}{c}\text { Any } \\
\text { Self- } \\
\text { Report }\end{array}$} & \multicolumn{2}{|c|}{ NDR Match } & \multirow[b]{2}{*}{ Total } & \multirow{2}{*}{$\begin{array}{c}\text { Match } \\
\text { Pct. }\end{array}$} \\
\hline & & & No & Yes & & \\
\hline No & No & No & 5,374 & 548 & 5,922 & 9.2 \\
\hline No & No & Yes & 4,037 & 891 & 4,928 & 18.1 \\
\hline Yes & No & No & 3,823 & 1,052 & 4,875 & 21.6 \\
\hline Yes & No & Yes & 2,979 & 991 & 3,970 & 25.0 \\
\hline Yes & Yes & No & 847 & 597 & 1,444 & 41.3 \\
\hline Yes & Yes & Yes & 1,256 & 1,459 & 2,715 & 53.7 \\
\hline \multicolumn{6}{|c|}{ Sum (All NDR Match = Yes) } & 5538 \\
\hline \multicolumn{6}{|c|}{ Sum (Any Driving Offense $=$ Yes) } & 4159 \\
\hline \multicolumn{6}{|c|}{ Sum (All NDR Match $=$ Yes OR Any Driving Offense $=$ Yes $)$} & 7641 \\
\hline \multicolumn{6}{|c|}{ Sum $($ NDR Match $=$ Yes AND Any Driving Offense $=$ Yes) } & 2056 \\
\hline
\end{tabular}

Table E-2

Population Totals, Aggregated by Subject

\begin{tabular}{|c|c|c|c|c|c|}
\hline \multirow{2}{*}{$\begin{array}{c}\text { Any } \\
\text { Criminal } \\
\text { Offense }\end{array}$} & \multirow{2}{*}{$\begin{array}{c}\text { Any } \\
\text { Driving } \\
\text { Offense }\end{array}$} & \multicolumn{3}{|c|}{ Any Self-Report } & \multirow[b]{2}{*}{ Total } \\
\hline & & No & Yes & Missing & \\
\hline No & No & 184,926 & 30,674 & 640 & 216,240 \\
\hline Yes & No & 14,949 & 12,498 & 113 & 27,560 \\
\hline \multirow[t]{2}{*}{ Yes } & Yes & 4,262 & 8,695 & 92 & 13,049 \\
\hline & & & Total, & $\begin{array}{r}\text { Total } \\
\text { onmissing }\end{array}$ & $\begin{array}{l}256,849 \\
256,004\end{array}$ \\
\hline
\end{tabular}


Table E-3

Population Estimates

\begin{tabular}{|c|c|c|c|}
\hline $\begin{array}{c}\text { Any } \\
\text { Criminal } \\
\text { Offense }\end{array}$ & $\begin{array}{c}\text { Any } \\
\text { Driving } \\
\text { Offense }\end{array}$ & $\begin{array}{l}\text { Any Self- } \\
\text { Report }\end{array}$ & $\begin{array}{l}\text { Est. No. } \\
\text { of NDR } \\
\text { Matches }\end{array}$ \\
\hline No & No & No & $17,112.4$ \\
\hline No & No & Yes & $5,546.0$ \\
\hline Yes & No & No & $3,225.9$ \\
\hline Yes & No & Yes & $3,119.8$ \\
\hline Yes & Yes & No & $1,762.1$ \\
\hline Yes & Yes & Yes & $4,672.6$ \\
\hline \multicolumn{3}{|c|}{ Sum(All NDR Match) } & $35,438.6$ \\
\hline \multicolumn{3}{|c|}{ Sum $($ Any Driving Offense $=$ Yes $)$} & $6,434.6$ \\
\hline \multicolumn{3}{|c|}{ Sum(Any Driving Offense $=$ No) } & $29,004.0$ \\
\hline \multicolumn{3}{|c|}{ Sum(All NDR or LAC) } & $42,053.0$ \\
\hline \multicolumn{4}{|c|}{ Pct. of Known Subjects with Driving Offenses: } \\
\hline \multicolumn{3}{|c|}{ Identified by LACs: } & $31.0 \%$ \\
\hline \multicolumn{3}{|c|}{ Identified by NDR: } & $84.3 \%$ \\
\hline
\end{tabular}

